\title{
Physical controls on phytoplankton physiology and production at a shelf sea front: a fast repetition-rate fluorometer based field study
}

\author{
C. Mark Moore ${ }^{1, *}$, David Suggett ${ }^{2}$, Patrick M. Holligan ${ }^{1}$, Jonathan Sharples ${ }^{1}$, \\ Edward R. Abraham ${ }^{3}$, Mike I. Lucas ${ }^{1}$, Tom P. Rippeth ${ }^{4}$, Neil R. Fisher ${ }^{4}$, \\ John H. Simpson ${ }^{4}$, David J. Hydes ${ }^{1}$ \\ ${ }^{1}$ Southampton Oceanography Centre, European Way, Southampton SO14 3ZH, UK \\ ${ }^{2}$ Department of Biological Sciences, University of Essex, Colchester CO4 3SQ, UK \\ ${ }^{3}$ National Institute of Water and Atmosphere, PO Box 14-901, Kilbirnie, Wellington, New Zealand \\ ${ }^{4}$ School of Ocean Sciences, University of Wales, Bangor, Menai Bridge, Gwynedd LL59 5AB, UK
}

\begin{abstract}
Observations of phytoplankton physiology collected using a fast repetition-rate fluorometer (FRRF) in the vicinity of a shelf-sea tidal-mixing front are presented. These data are combined with more traditional ${ }^{14} \mathrm{C}$-based measurements and observations of environmental parameters, including estimates of turbulent dissipation rates, in order to investigate the influence of physical forcing on the productivity of the system. Low nutrient concentrations on the stratified side of the front result in a reduction of photosynthetic efficiency. Conversely, the high degree of vertical mixing on the mixed side of the front constrains the ability of phytoplankton to adjust their photosynthetic apparatus to the ambient irradiance field. Redistribution of phytoplankton biomass and variations in physiological parameters also result from the spring-neap tidal cycle. FRRF- and ${ }^{14} \mathrm{C}$-derived physiological measurements are compared in the context of environmental gradients in the region. A strong correlation was found between independently measured functional absorption cross-sections $\left(\sigma_{\mathrm{PSII}}\right)$ and maximal photosynthetic rates $\left(P_{\max }^{*}\right)$. Such a relationship was unlikely to have been causative and may have resulted from shifts in the balance between light-harvesting and carbon fixation across the front. The association of changes in $P_{\text {max }}^{*}$ with variations in $\sigma_{\text {PSI }}$ provided the basis for the development of an empirical model, specific to the system and time of study, which utilised FRRF data to extrapolate between primary productivity rates measured at fixed sites. When applied to highresolution cross-frontal data, the model suggested small-scale variations in productivity related to both spatial and temporal physical forcing including the spring-neap cycle.
\end{abstract}

KEY WORDS: Fronts $\cdot$ Biological-physical interactions $\cdot$ Fluorescence $\cdot$ Primary production

\section{INTRODUCTION}

It has long been recognised that phytoplankton concentrations are strongly influenced by physical processes, particularly in temperate shelf seas, where high levels of chlorophyll a characterise the boundaries between fully mixed and stratified waters in summer, as well as the seasonal thermocline (e.g. Pingree et al. 1975, Holligan et al. 1984, Sharples et al. 2001). However serious gaps remain in our ability to estimate and predict the distributions of phytoplankton biomass and productivity in such highly dynamic regions, caused by an incomplete knowledge of the effects of environmental variability on phytoplankton physiology. For example, the spring-neap cycle of tidal dissipation has long been recognised as being important within shelfsea tidal-mixing fronts (Pingree et al. 1975), but the physiological response of the phytoplankton community to forcing at this scale has remained difficult to quantify. Also the relative importance of passive trans- 
port and active growth in causing the enhanced phytoplankton biomass observed at fronts continues to be debated (LeFevre 1986, Franks 1992a,b).

These problems largely arise from a mismatch between the scales at which the biological and physical measurements are routinely made. As a result of the relative under-sampling of variations in phytoplankton physiology, the biological response to physical forcing is typically inferred from variations in phytoplankton biomass rather than changes in the rates of growth or turnover of the population. This distinction is fundamental, as the limitation of standing stock or growth rate are quite different ecological concepts.

The growing use of active fluorescence techniques such as the fast repetition-rate fluorometer (FRRF) is extending the range of scales at which phytoplankton physiology can be observed in situ (Kolber et al. 1990, Falkowski et al. 1991, Behrenfeld et al. 1996, Suggett et al. 2001). Such techniques therefore have the potential to quantify rapid changes in productivity in response to environmental forcing at the ecologically important scales of fronts and other mesoscale phenomena.

The objective of the present study was to investigate the influence of small-scale physical forcing on the physiology and production of phytoplankton in the vicinity of a shelf-sea tidal-mixing front. Detailed physical and environmental data were collected in combination with in situ observations of phytoplankton physiological variability using FRRF and more traditional techniques. The hypothesis is investigated that physical forcing, by governing the availability of nutrients and light, controls the physiological state and hence productivity of the phytoplankton populations associated with different regions of the front. The study represents one of the first attempts to use the increased sampling resolution achievable with the FRRF technique in order to observe changes in physiology and production in a highly dynamic region at physically relevant scales.

\section{MATERIALS AND METHODS}

Observations were made during an $11 \mathrm{~d}$ period from 2 to 13 August 1999 at 4 fixed stations and along a cross-frontal transect in the western English Channel (Fig. 1). Neap tides occurred in the region on 6 August, while spring tides occurred on 13 August. Each fixed station was occupied for $25 \mathrm{~h}$ in order to span 1 diel cycle and 2 complete tidal cycles. The stratified sites, U2 (mean depth $118 \mathrm{~m}$ ) and E (mean depth $72 \mathrm{~m}$ ), were each occupied once on 8 to 9 and 10 to 11 August 1999 respectively. The more mixed site, $M$ (mean depth $105 \mathrm{~m})$ was occupied twice; firstly during neap tidal conditions on 6 to 7 August 1999, and secondly during spring tides on 12 to 13 August 1999 (these stations will be referred to as M2 and M3 respectively).

For each fixed station, approximately hourly profiles of salinity temperature and phytoplankton physiological parameters were obtained using a CTD/FRRF package. At 3 of these stations (U2, M2 and M3), CTD profiles were alternated with sets (5 to 6 ) of vertical profiles of velocity-gradient microstructure collected using a free-fall turbulence profiler, FLY (Dewey et al. 1987). These data provided $25 \mathrm{~h}$ time-series of the vertical structure of the rate of dissipation of turbulent kinetic energy $(\varepsilon)$ following the method described in Sharples et al. (2001).

Cross-frontal transects from $\mathrm{M}$ to U2 were performed on 2, 8 and 9 August 1999. On 2 and 8 August, data were collected using a SeaSoar-towed undulating body with FRRF attached, while the CTD/FRRF package was utilised for the transect (Stns U2, L1 to L6, M; Fig. 1) on 9 August. The first and second runs with the SeaSoar were thus collected around 2 to $3 \mathrm{~d}$ after maximum spring and neap tides respectively. Such timing was likely to have corresponded to the extremes of the spring-neap adjustment of frontal position and stratification (e.g. Simpson \& Bowers 1981, Sharples \& Simpson 1996).

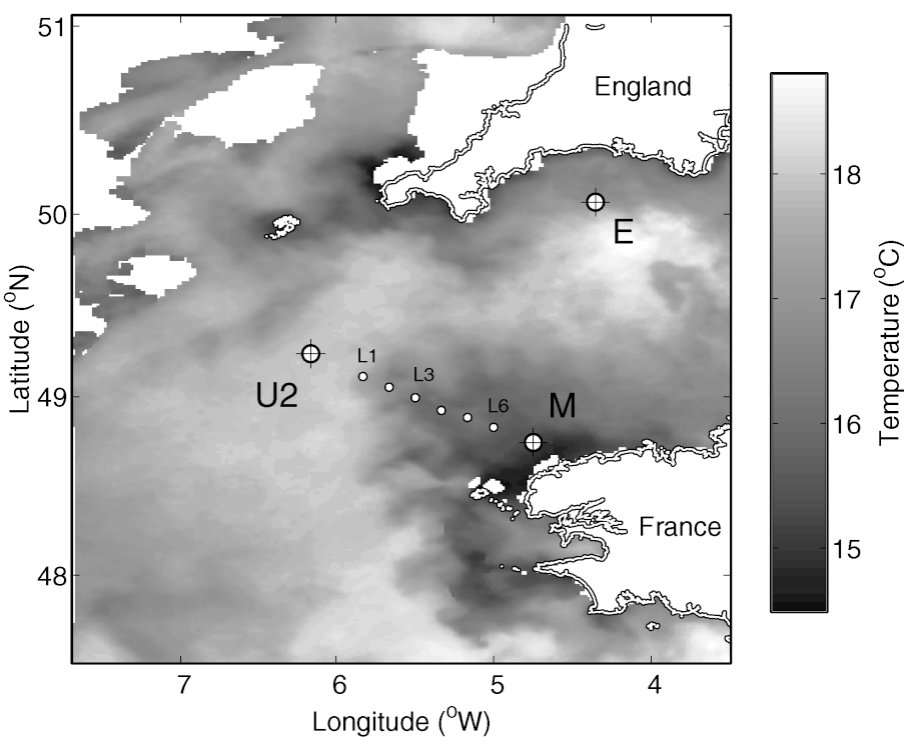

Fig. 1. Locations of 4 fixed stations (U2, E, M) and CTD transect occupied in August 1999 superimposed on advanced very high resolution radiometry (AVHRR) sea-surface temperature (SST) image of 25 July 1999. Tidal front marks boundary between well-mixed (lower SST, Stn M) and stratified (higher SST, Stn U2) waters. On this date, intermediate conditions prevailed at Stn E (stratified site). For clarity, not all cross-frontal CTD stations (L1 to L6) are labelled. White areas with borders are land; white areas on top left indicate regions of cloud 
Sampling. Water samples were collected using $10 \mathrm{l}$ Niskin bottles attached to the CTD rosette. Water was filtered through Whatman GF/F filters for measurement of chlorophyll a on a Turner Designs digital fluorometer, following the method of Welschmeyer (1994). Filters were also collected and frozen for subsequent pigment analysis (HPLC) and spectral absorption measurements. Pigments were analysed according to the methods of Barlow et al. (1997) on a 'Thermo Separation Products' HPLC. All values of chlorophyll a (chl a) reported are HPLC-derived or scaled to the HPLC value using the observed relationship between the 2 techniques (HPLC chl $a=0.63$ fluorometric chl $a$, $\mathrm{r}^{2}=0.985, \mathrm{n}=49$ ). Phytoplankton absorption spectra were measured on an Hitachi U-3000 spectrophotometer fitted with a $\varphi 60$ integrating sphere following Tassan \& Ferrari (1995). Depigmentation was achieved using $\mathrm{NaClO}$, and a wavelength-independent path length-amplification factor was determined from cultures of eukaryotic algae. Absorption spectra were normalised to chlorophyll $a$ in order to generate the wavelength-dependent chlorophyll-specific absorption $\left(a^{*}(\lambda)\right)$. Spectra were averaged between 400 and $700 \mathrm{~nm}$ to generate the mean chlorophyll-specific absorption coefficient $\left(a^{*}\right)$. No absorption data were available from Site E, so that values of $a^{*}$ for this site were estimated using the mean value from the other sites. Nutrient samples for nitrate, silicate and phosphate were analysed on board with a Burkard AA-II autoanalyser, using standard techniques.

${ }^{14} \mathrm{C}$ experiments. A number of short-term (1 to $2 \mathrm{~h}$ ) $P^{*}$ versus $E$ (irradiance) incubations were performed in a photosynthetron cooled to sea-surface temperature. Samples were incubated in $80 \mathrm{ml}$ bottles, each of which was inoculated with $100 \mu \mathrm{l}$ of $100 \mu \mathrm{Ci} \mathrm{ml}^{-1}$ buffered $\mathrm{NaH}^{14} \mathrm{CO}_{3}$ working stock, resulting in a final activity of around $0.125 \mu \mathrm{Ci} \mathrm{ml} l^{-1}$. Data from these samples were used to calculate the chlorophyll-specific maximum carbon-uptake rate $\left(P^{*}{ }_{\max }\right)$, the maximum light-utilisation coefficient $\alpha^{*}$ (referred to as $\alpha^{*}{ }_{14 \mathrm{C}}$ when specific to $P^{*}$ vs $E$-derived values) and the light-saturation parameter $E_{\mathrm{k}}$ (Table 1). Irradiance was measured at all positions within the photosynthetron using a QSL-100 quantum sensor (Biospherical Instruments). Values of $\alpha^{*}{ }_{14} \mathrm{C}$ were corrected to correspond to a 'white' spectrum using the measured chlorophyllspecific absorption and lamp spectra as described by various authors (e.g. Dubinsky et al. 1986, Cleveland et al. 1989, Suggett et al. 2001). The maximum quantum yield of carbon fixation $\left(\phi_{C, \text { max }}=\alpha^{*}{ }_{14 C} / a^{*}\right.$, Table 1) was also calculated from the $P^{*}$ vs $E$ and absorption measurements (e.g. Cleveland et al. 1989, Babin et al. 1996). Samples were collected from a number of depths at the U2, E, M2, M3 and L3 stations (Fig. 1).

Additionally, on-deck simulated in situ ${ }^{14} \mathrm{C}$ incubations were performed at each of the 4 sites occupied for $25 \mathrm{~h}$ (U2, E, M2 and M3) following protocols previously adopted for this region (Holligan et al. 1984). Samples were collected at 6 depths corresponding to 95, 55, 30, $14,4.5$ and $1 \%$ of surface irradiance, and then incubated on deck for 6 to $8 \mathrm{~h}$ at sea-surface temperature in an incubator shaded with neutral-density filters to

Table 1. Notation used throughout paper. a.u.: arbitrary units; D: dimensionless; PQ: photosynthetic quotient; FRRF: fast repetition-rate fluorometer

\begin{tabular}{|c|c|c|}
\hline $\begin{array}{l}\text { Technique } \\
\text { Parameter }\end{array}$ & Definition & Units \\
\hline \multicolumn{3}{|l|}{${ }^{14} \mathrm{C}$} \\
\hline$\alpha^{*}\left(\alpha^{*}{ }_{14} \mathrm{C}\right)$ & Maximum light-utilisation coefficient & $\begin{array}{l}\operatorname{mg~C}(\mathrm{mg} \mathrm{chl} a)^{-1} \mathrm{~h}^{-1} \\
\left(\mu \mathrm{mol} \text { photons } \mathrm{m}^{-2} \mathrm{~s}^{-1}\right)^{-1}\end{array}$ \\
\hline$P_{\max }^{*}$ & Maximum photosynthetic rate & $\operatorname{mg~C}(\operatorname{mg} \operatorname{chl} a)^{-1} \mathrm{~h}^{-1}$ \\
\hline$E_{\mathrm{k}}$ & Light saturation parameter $\left(=P_{\max }^{*} / \alpha^{*}\right)$ & $\mu \mathrm{mol}$ photons $\mathrm{m}^{-2} \mathrm{~s}^{-1}$ \\
\hline$a^{*}$ & Chlorophyll $a$-specific absorption coefficient & $\mathrm{m}^{2}(\mathrm{mg} \mathrm{chl} a)^{-1}$ \\
\hline$\phi_{\mathrm{C}, \max }$ & $\begin{array}{l}\text { Maximum quantum yield for carbon fixation } \\
\left(=\alpha^{*} / a^{*}\right)\end{array}$ & mol C (mol photons) $)^{-1}$ \\
\hline \multicolumn{3}{|l|}{ FRRF } \\
\hline$F_{0}, F_{\mathrm{m}}$ & $\begin{array}{l}\text { Minimal and maximal fluorescence yields } \\
\text { measured in dark }\end{array}$ & a.u. \\
\hline$F_{0}^{\prime}, F^{\prime}, F_{\mathrm{m}}^{\prime}$ & $\begin{array}{l}\text { Minimal, steady state and maximal fluorescence } \\
\text { yields measured under ambient irradiance }\end{array}$ & a.u. \\
\hline$F_{\mathrm{v}}$ & Variable fluorescence $\left(=F_{\mathrm{m}}-F_{0}\right)$ & a.u. \\
\hline$F_{\mathrm{q}}^{\prime}$ & $\begin{array}{l}\text { Change in fluorescence yield measured under } \\
\text { ambient light }\left(=F_{m}^{\prime}-F^{\prime}\right)\end{array}$ & a.u. \\
\hline$F_{\mathrm{v}} / F_{\mathrm{m}}$ & Maximum quantum yield of photochemistry & $\mathrm{D}$ \\
\hline$F_{\mathrm{q}}^{\prime} / F_{\mathrm{m}}{ }^{\prime}$ & $\begin{array}{l}\text { Quantum yield of photochemistry measured } \\
\text { under ambient light }\end{array}$ & $\mathrm{D}$ \\
\hline$\sigma_{\mathrm{PSII}}$ & $\begin{array}{l}\text { Functional absorption cross-section of } \\
\text { Photosystem II in dark }\end{array}$ & $\AA^{2}$ quanta $^{-1}$ \\
\hline$\sigma_{\mathrm{PSII}}{ }^{\prime}$ & $\begin{array}{l}\text { Functional absorption cross-section of } \\
\text { Photosystem II under ambient light }\end{array}$ & $\AA^{2}$ quanta $^{-1}$ \\
\hline $\begin{array}{r}\text { Derived } \\
\alpha^{*}{ }_{\text {FRRF }}\end{array}$ & $\begin{array}{l}\text { Maximum light-utilisation coefficient derived } \\
\text { from FRRF-based observations } \\
\left(=\mathrm{A} \sigma_{\mathrm{PSII}} f \text { PSII:chl } \mathrm{PQ}^{-1}\right)\end{array}$ & $\begin{array}{l}\operatorname{mg~C}(\mathrm{mg} \mathrm{chl} a)^{-1} \mathrm{~h}^{-1} \\
\left(\mu \mathrm{mol} \text { photons } \mathrm{m}^{-2} \mathrm{~s}^{-1}\right)^{-1}\end{array}$ \\
\hline
\end{tabular}


simulate the irradiance at the sampling depth. No data on the spectrum of the underwater light field were available. Spectral differences between the in situ irradiance and the irradiance within the on-deck incubators therefore remains a potential cause of discrepancy when comparing the simulated in situ measurements with other data (e.g. Boyd et al. 1997, Suggett et al. 2001).

As samples were all incubated at surface temperatures, differences between incubation and in situ temperatures are a possible source of artefacts. This was likely to have been of greatest importance at the U2 site, where temperatures within the thermocline were $\sim 5^{\circ} \mathrm{C}$ lower than surface values.

FRRF measurements. A Fastracka FRRF (Chelsea Scientific Instruments) was attached to the CTD frame during each of the CTD casts and attached to the SeaSoar undulator during the cross-frontal transects. FRRF deployment and analysis was performed using methods similar to those of Suggett et al. (2001), although a faster sampling rate of 1 measurement every $\sim 7 \mathrm{~s}$ eliminated the need for the CTD package to be held at fixed depths during vertical profiling. Variable chlorophyll a fluorescence was stimulated using a saturating sequence of $1001.1 \mu$ s flashes applied at $2.8 \mu$ s intervals. Flashes were generated using a bank of blue-light LEDs, the peak of the emission spectrum was at $478 \mathrm{~nm}$ with an approximately $30 \mathrm{~nm}$ halfbandwidth. The fluorescence yield following each flash was recorded internally for download at a later time. Fluorescence transients were then fitted to the biophysical model of Kolber et al. (1998), in order to derive the initial $\left(F_{0}\right)$ and maximal $\left(F_{\mathrm{m}}\right)$ fluorescence, as well as the functional absorption cross section of Photosystem II $\left(\sigma_{\mathrm{PSII}}\right.$, expressed in units of $\mathrm{m}^{2}$ or $\AA^{2}$ quanta $^{-1}$ ) see Table 1. Maximum photochemical efficiency was calculated as $\left(F_{\mathrm{m}}-F_{0}\right) / F_{\mathrm{m}}=F_{\mathrm{v}} / F_{\mathrm{m}}$ (e.g. Geider et al. 1993, Kolber \& Falkowski 1993, Falkowski \& Raven 1997).

The curve-fitting procedure was performed in 2 ways, the first utilising the custom software provided by the instrument manufacturers (FRS v1.4) and the second using software run in MATLAB ${ }^{\mathrm{TM}}$, based on original codes provided to the FRRF community by S. Laney (V4). Tests performed to assess the sensitivity of parameter retrieval to raw-data analysis indicated only minor differences (typically $<10 \%$ ) between the various methods for the current data set (Moore 2002). All values quoted in the current contribution were fitted by setting the connectivity parameter to zero (see Kolber et al. 1998), using an edited version of V4, which also allowed for a greater number of iterations before convergence (see release notes with V5 available at http://picasso.oce.orst.edu/ORSOO/FRRF/). Fluorescence transients were corrected for non-linearities in instrument response using transients recorded during the analysis of a chlorophyll extract.

The CI Fastracka FRRF is configured with 2 sampling volumes, 1 open to ambient irradiance and 1 shaded from the in situ light field. This set-up allowed measurements to be made of initial and saturated fluorescence under conditions of ambient light and after rapid removal into the dark. Adopting the nomenclature of Oxborough \& Baker (1997), parameters measured in the sample area exposed to ambient irradiance thus correspond to $F^{\prime}, F_{\mathrm{m}}{ }^{\prime}$ and $F_{\mathrm{q}}{ }^{\prime} / F_{\mathrm{m}}{ }^{\prime}$, under daylight conditions (Table 1 ). The terms $F_{\mathrm{v}} / F_{\mathrm{m}}$ and $\sigma_{\text {PSII }}$ refer to dark-acclimated values measured after the relaxation of all photochemical and nonphotochemical quenching. For the present study reported values of $F_{\mathrm{v}} / F_{\mathrm{m}}$ and $\sigma_{\mathrm{PSII}}$ are from casts performed during the night period. Reported values of $\sigma_{\text {PSII }}$ (or $\sigma_{\text {PSII }}{ }^{\prime}$ under daylight, Table 1) were measured in the dark chamber in order to minimise noise introduced to the fluorescence signal by ambient photons in the red part of the spectrum, which are detected by the FRRF. This problem of ambient light, which was particularly acute at the highly stratified U2 site, also resulted in all $\sigma_{\mathrm{PSII}}{ }^{\prime}$ data from the upper $2 \mathrm{~m}$ being discarded from Stns E, M2 and M3 and from the upper $5 \mathrm{~m}$ for Stn U2.

Photosynthetically available radiation (PAR) was measured using a CI $2 \pi(400-700 \mathrm{~nm})$ PAR sensor interfaced with the FRRF. The broadband vertical diffuse-attenuation coefficient for PAR $\left(K_{\mathrm{d}}\right)$ was calculated from the vertical PAR profile. Hereafter PAR is referred to as irradiance $(E)$.

In order to obtain higher resolution information on chlorophyll distributions, FRRF measurements of $F_{\mathrm{m}}$ were calibrated against discrete chlorophyll a samples from the 4 fixed stations and collected underway during the cross-frontal transects $\left(\mathrm{R}^{2}>0.76, \mathrm{n}>35\right.$ for all individual stations).

FRRF-derived $\boldsymbol{P}^{*}$ and $\boldsymbol{\alpha}^{*}$. The electron transport rate (ETR) through a functional PSII reaction centre can be calculated from fluorescence-based physiological measurements using photosynthetic models (Genty et al. 1989, Kolber \& Falkowski 1993, Flameling \& Kromkamp 1998, Suggett et al. 2001). In order to convert the ETR to an equivalent chlorophyll-specific carbonfixation rate $\left(P^{*}\right)$, values for the ratio of PSII reaction

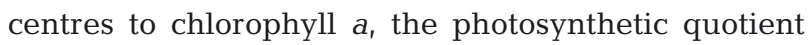
$\left(\mathrm{PQ}, \mathrm{mol} \mathrm{O}_{2}\right.$ evolved $\mathrm{mol}^{-1}$ carbon fixed) and the maximum quantum yield of electron transport through PSII $\left(0.25 \mathrm{~mol} \mathrm{O}_{2}\right.$ (mol photons) $^{-1}$ ) are required (Kolber \& Falkowski 1993). An FRRF-based estimate for $\alpha^{*}$ (expressed in terms of equivalent carbon uptake) can thus be calculated as (Kolber \& Falkowski 1993, Babin et al. 1996, Falkowski \& Raven 1997, Behrenfeld et al. 1998): 


$$
\alpha_{\text {FRRF }}^{*}=A \sigma_{\mathrm{PSII}} f \text { PSII:chl PQ }{ }^{-1}
$$

where PSII:chl is the ratio of PSII reaction centres per chl a molecule (mol PSII [mol chl a $]^{-1}$ ) and the factor $A$ is assumed to be constant $(=0.0729)$; it includes a factor of 0.25 and factors to convert moles of carbon and chl $a$ to $\mathrm{mg}$, and $\mathrm{s}^{-1}$ to $\mathrm{h}^{-1}$. The factor $f$ denotes the fraction of functional PSII reaction centres and, for the purposes of the present study, is estimated from $F_{\mathrm{v}} / F_{\mathrm{m}} / 0.65$ (Kolber \& Falkowski 1993), the constant being the maximum value which is typically found for $F_{\mathrm{v}} / F_{\mathrm{m}}$ (e.g. Kolber et al. 1988). This calculation contains a number of assumptions, for example the value 0.65 may not be universally valid for all taxa, also the degree of connectivity between PSII reaction centres will alter the relationship between $f$ and $F_{\mathrm{v}} / F_{\mathrm{m}}$. As such, the ratio $F_{\mathrm{v}} / F_{0}$, which is hyperbolically related to $F_{\mathrm{v}} / F_{\mathrm{m}}$, has been considered to be more accurate for the estimation of $f$ (e.g. Crofts et al. 1993, Babin et al. 1996). For the current data, use of $F_{\mathrm{v}} / F_{0}$ would have resulted in values of $\alpha^{*}{ }_{\text {FRRF }}$ that were, on average, lower by $\sim 30$ to $40 \%$.

As $\sigma_{\text {PSII }}$ is spectrally dependent (Kolber \& Falkowski 1993), $\alpha^{*}{ }_{\text {FRRF }}$ also required adjustment (as described earlier for $\alpha^{*}{ }_{14}$ C) in order to correspond to a 'white' spectrum, this time using the measured FRRF excitation spectra (Babin et al. 1996, Suggett et al. 2001).
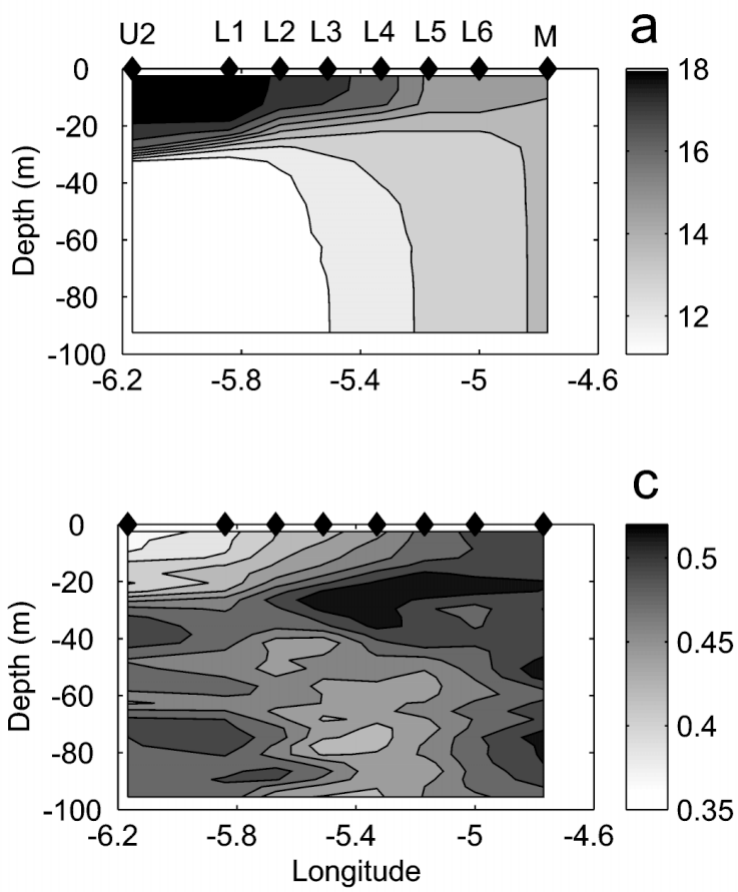

\section{RESULTS}

\section{General hydrography, chlorophyll a distribution and nutrient concentrations}

The frontal position could be clearly observed in the SST distribution shown by an advanced very high resolution radiometry (AVHRR) image for 25 July (Fig. 1). On the mixed side of the front (i.e. around Stn $M)$, surface temperatures were around $14^{\circ} \mathrm{C}$, increasing to over $18^{\circ} \mathrm{C}$ in the surface waters on the stratified side. Vertical temperature structure through the frontal region (Stns U2 to M) was typical of a tidal mixing front, progressing from highly stratified conditions at U2, to more mixed at M (Fig. 2a). Dissipation rates measured with the FLY profiler were higher at M than at U2, and increased between neap (Stn M2) and spring (Stn M3) tides at M in response to the increasing tidal currents (Fig. 3). Tidal mixing was apparent at the surface for Stn M3, the dissipation rate at $10 \mathrm{~m}$ being an order of magnitude greater than during M2 sampling. In accordance with the enhanced dissipation rates during spring tides, the water column was observed to be fully mixed for the majority of the M3 profiles, while some near-surface stratification was apparent at M2 (Fig. 3c,e). Conversely, the fixed Stn U2 was highly stratified, a marked minimum in the dissipation rate being associated with the thermocline region,
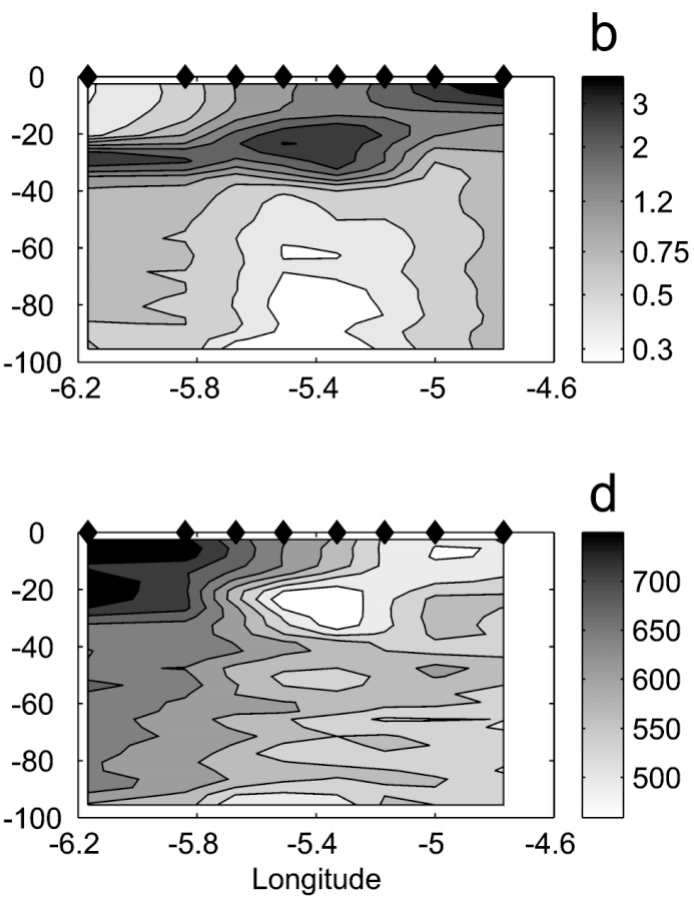

Fig. 2. Frontal cross-sections of (a) temperature $\left({ }^{\circ} \mathrm{C}\right)$, (b) chlorophyll a $\left(\mathrm{mg} \mathrm{m}^{-3}\right)$, (c) $F_{\mathrm{v}} / F_{\mathrm{m}}$ and (d) $\sigma_{\mathrm{PSII}}\left(\AA^{2}\right.$ quanta $\left.{ }^{-1}\right)$. Chlorophyll values are FRRF $F_{\mathrm{m}}$-calibrated against discrete bottle samples. All data were collected overnight on 9 August 1999 during a CTD survey. : Locations of individual CTD casts. Station names are indicated in (a) 


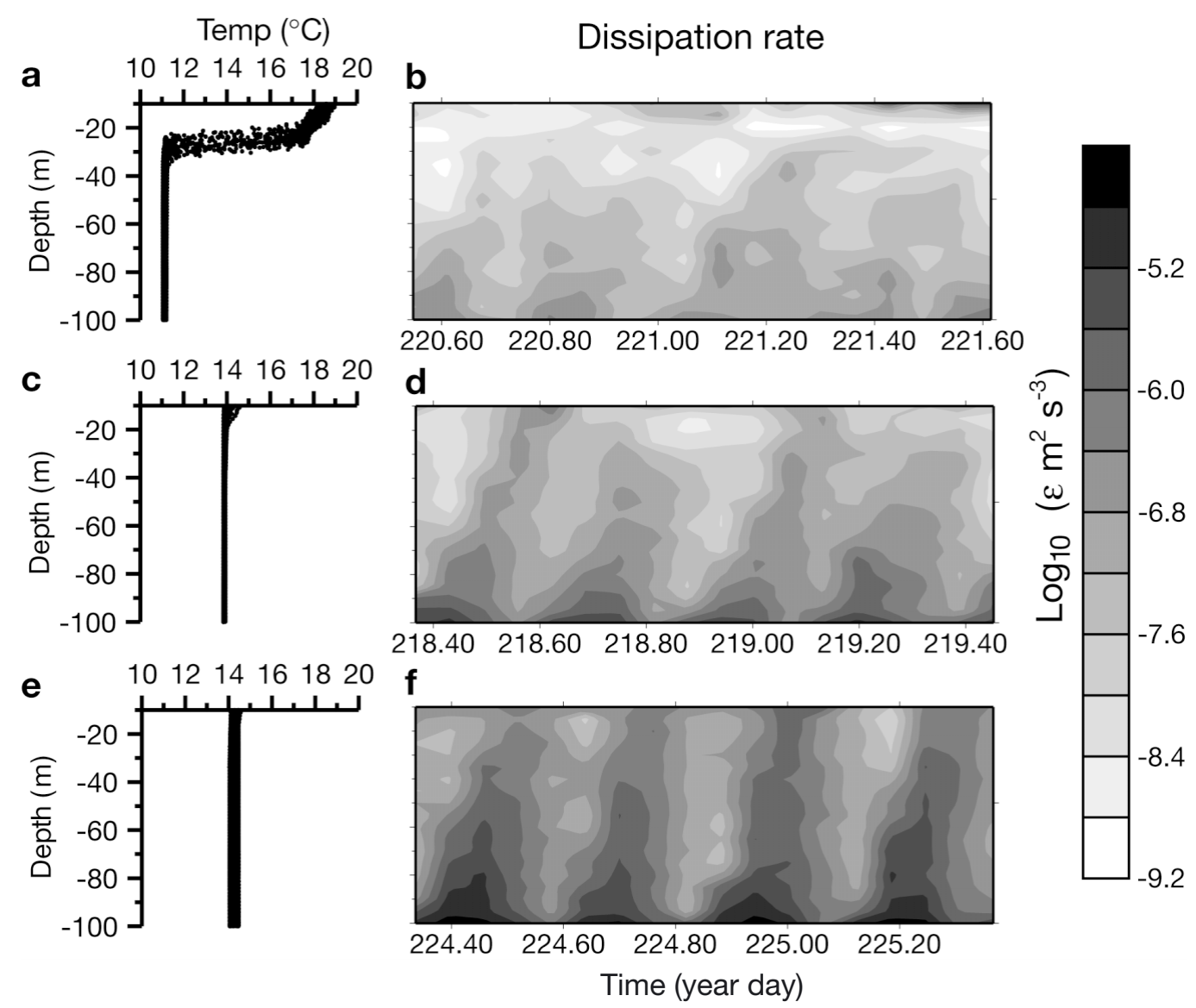

Fig. 3. Physical variability between the 3 fixed stations for which FLY (free-fall turbulence profiler) profiles were obtained. (a,b) U2 (8 to 9 August 1999); (c,d) M2 (6 to 7 August 1999); (e,f) M3 (12 to 13 August 1999). (a,c,e) Temperature as a function of depth for all CTD casts at the 3 sites. (b,d,f) Rate of dissipation of turbulent kinetic energy; contour plots of dissipation against time (day of year 1999) and depth were produced using mean dissipation value from each of the profile bursts averaged into $5 \mathrm{~m}$ depth bins (see Sharples et al. 2001). Plots are thus composed of between 19 and 21 approximately evenly spaced depth profiles of dissipation

whereby $\varepsilon$ was typically as low as $10^{-8}$ to $10^{-9} \mathrm{~m}^{2} \mathrm{~s}^{-3}$ (Fig. 3a,b and Sharples et al. 2001). Stn E was moderately stratified, being characterised by a more diffuse thermocline than that at U2 (data not shown).

The distribution of chlorophyll a was closely associated with the physical structure of the front (Fig. 2b). There was a strong correspondence between the regions of maximum phytoplankton pigment and the regions of maximum thermal gradient. The highest observed chlorophyll a levels were associated with the thermocline region on the stratified side of the front, locally reaching $>50 \mathrm{mg} \mathrm{m}^{-3}$ at Stn U2 (Sharples et al. 2001). Relatively high levels were also associated with the region in which the thermocline outcropped at the surface. Intermediate levels of chlorophyll a (around $1 \mathrm{mg} \mathrm{m}^{-3}$ ) were observed within fully mixed water columns, whilst the lowest surface values $\left(<0.3 \mathrm{mg} \mathrm{m}^{-3}\right)$ were measured at Stn U2.

Microscope observations showed that the phytoplankton populations were dominated by a mixed diatom and dinoflagellate assemblage at Stn $\mathrm{M}$ and by small unidentified eukaryotic flagellates and a coccolithophore (Calyptrosphaera oblonga) in the surface water and thermocline respectively at Stn U2. In the region of Stn E, a bloom of the coccolithophore Emiliania huxleyi was observed during the preceding 2 to $3 \mathrm{wk}$, but had declined by the time of our observations (Fileman et al. 2002). HPLC data was consistent with the distribution of different taxonomic groups. A high 19-hexanoyloxyfucoxanthin (hex) to chlorophyll a ratio was evident at Stn U2, particularly within the thermocline region, indicating a prymnesiophyte population (e.g. Jeffrey 1997). In contrast, relatively high fucoxanthin to chlorophyll $a$ ratios and some peridinin indicated the presence of diatoms and some dinoflagellates within the community at Stn M during both neap and spring tides (Jeffrey 1997). A relatively high chlorophyll $b$ to chlorophyll $a$ ratio observed at this site may have been due to dinoflagellates containing chlorophyll $b$, as has previously been reported for the region (Sournia et al. 1992). 
Concentrations of nitrate, phosphate and silicate were highly positively correlated throughout the frontal region. As expected (e.g. Holligan 1981), nitrate concentrations increased from undetectable in surface waters on the stratified side of the front, through medium values (around $2.4 \mathrm{mmol} \mathrm{m}^{-3}$ ) on the mixed side, to the highest values (around $5.7 \mathrm{mmol} \mathrm{m}^{-3}$ ), which were observed in the bottom mixed waters on the stratified side, as previously reported (Sharples et al. 2001).

\section{Light variability}

The mean diffuse-attenuation coefficient for irradiance $\left(K_{\mathrm{d}}\right)$ calculated from vertical profiles at the fixed sites ranged from $0.09 \mathrm{~m}^{-1}$ at Stn U2, through 0.11 to $0.15 \mathrm{~m}^{-1}$ at Stn $\mathrm{M}$ to $0.19 \mathrm{~m}^{-1}$ at Stn E. For profiles collected at the U2 and $\mathrm{M}$ sites, $K_{\mathrm{d}}$ was found to be correlated with the chlorophyll concentration (Fig. 4) and a marked increase in attenuation was observed within the dense sub-surface chlorophyll maximum at U2. The sub-surface chlorophyll peak at the U2 site at a depth of $\sim 30 \mathrm{~m}$ typically coincided with the $1 \%$ light level, with the majority of the chlorophyll lying between the 0.1 and $7 \%$ light level. On the mixed side of the front, vertical mixing would have affected the integrated irradiance experienced by the phytoplankton. During occupation of the M3 station, $K_{\mathrm{d}}$ was uniform throughout the water column, the $0.1 \%$ light depth being just above mid-depth at $46 \mathrm{~m}$. Simple scaling

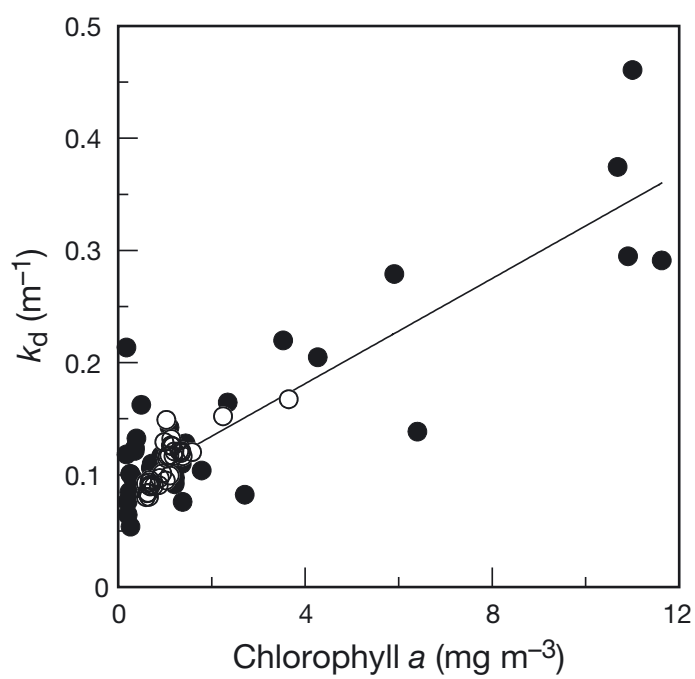

Fig. 4. PAR attenuation coefficient $\left(K_{\mathrm{d}}\right)$, as a function of chlorophyll a concentration for 3 vertical profiles at Stns U2 $(\bullet)$ and $\mathrm{M}(\mathrm{O})$. Data are from CTD downcasts only. $K_{\mathrm{d}}=\Delta(\ln (E)) / \Delta \mathrm{z}$ was calculated at vertical resolution of the individual irradiance measurements (1 to $4 \mathrm{~m}$ ); chlorophyll is from calibrated FRRF $F_{\mathrm{m}}$ measurements. Fitted line is Model II linear regression: $K_{\mathrm{d}}=0.082+0.025 \mathrm{chl} a, \mathrm{r}^{2}=0.763, \mathrm{n}=95, \mathrm{p}<0.001$ arguments can be used to derive an estimate of the mixing time-scale over a distance, $L$, within a mixed water column, $t_{\text {mix }}=L^{2 / 3} \varepsilon^{-1 / 3}$ (e.g. Denman \& Gargett 1983). Thus, choosing a typical dissipation rate of between $1 \times 10^{-6}$ and $1 \times 10^{-7} \mathrm{~m}^{2} \mathrm{~s}^{-3}$ (Fig. 3), phytoplankton cells at Stn M3 could be expected to be mixed through the whole column on a time-scales of 1 to $2 \mathrm{~h}$. On average, individual cells would therefore have spent a greater proportion of the daily period below the $0.1 \%$ light level than above, with an average irradiance of around 6 to $7 \%$ of surface values experienced over the diel period.

\section{Frontal-scale variations in physiology}

Clear relationships were observed between the large-scale physical structure and the physiology of the phytoplankton populations associated with various regions of the front during the CTD survey on 9 and 10 August 1999 (Fig. 2c,d). The broad-scale patterns of $F_{\mathrm{v}} / F_{\mathrm{m}}$ and $\sigma_{\mathrm{PSII}}$ indicated that populations on the mixed and stratified side of the front were physiologically distinct. Vertical variations associated with populations within and above the thermocline were also apparent (Fig. 2c,d).

The broad-scale patterns of physiological variability were investigated at higher resolution using the FRRF on the SeaSoar undulator (Fig. 5). Populations on the mixed side of the front had high values of $F_{\mathrm{v}} / F_{\mathrm{m}}$ (e.g. mean $\pm \mathrm{SD}=0.54 \pm 0.02$ and $0.56 \pm 0.02$ for the first and second SeaSoar runs respectively; Fig. 5). Relatively high values were also associated with the thermocline and the surface region of the transitional zone (Figs. 2c \& 5). The photochemical efficiency was lowest for the surface population on the highly stratified side, with $F_{\mathrm{v}} / F_{\mathrm{m}}=0.35 \pm 0.02$ for the upper $5 \mathrm{~m}$ at Stn U2. Populations trapped beneath the thermocline in the middle portion of the front also had lower values of $F_{\mathrm{v}} / F_{\mathrm{m}}$ $(0.42 \pm 0.03)$. Strong horizontal gradients in $F_{\mathrm{v}} / F_{\mathrm{m}}$ were associated with the horizontal temperature gradients of the front (Fig. 5).

A movement of the frontal position resulted from increasing stratification during neap tides. Such springneap adjustment of tidal mixing fronts is caused by a cycle of mixing and stratification within the same water mass as a result of changes in the balance between surface heat inputs and tidal stirring, rather than by advection (Sharples \& Simpson 1996). During spring tides, the photosynthetic efficiency of phytoplankton in the transitional region was significantly higher over a $>20 \mathrm{~km}$ cross-frontal distance (Fig. 5). Temporal variations in the regions of physiologically distinct communities closely followed the patterns of frontal movement. The SeaSoar sections thus provide 


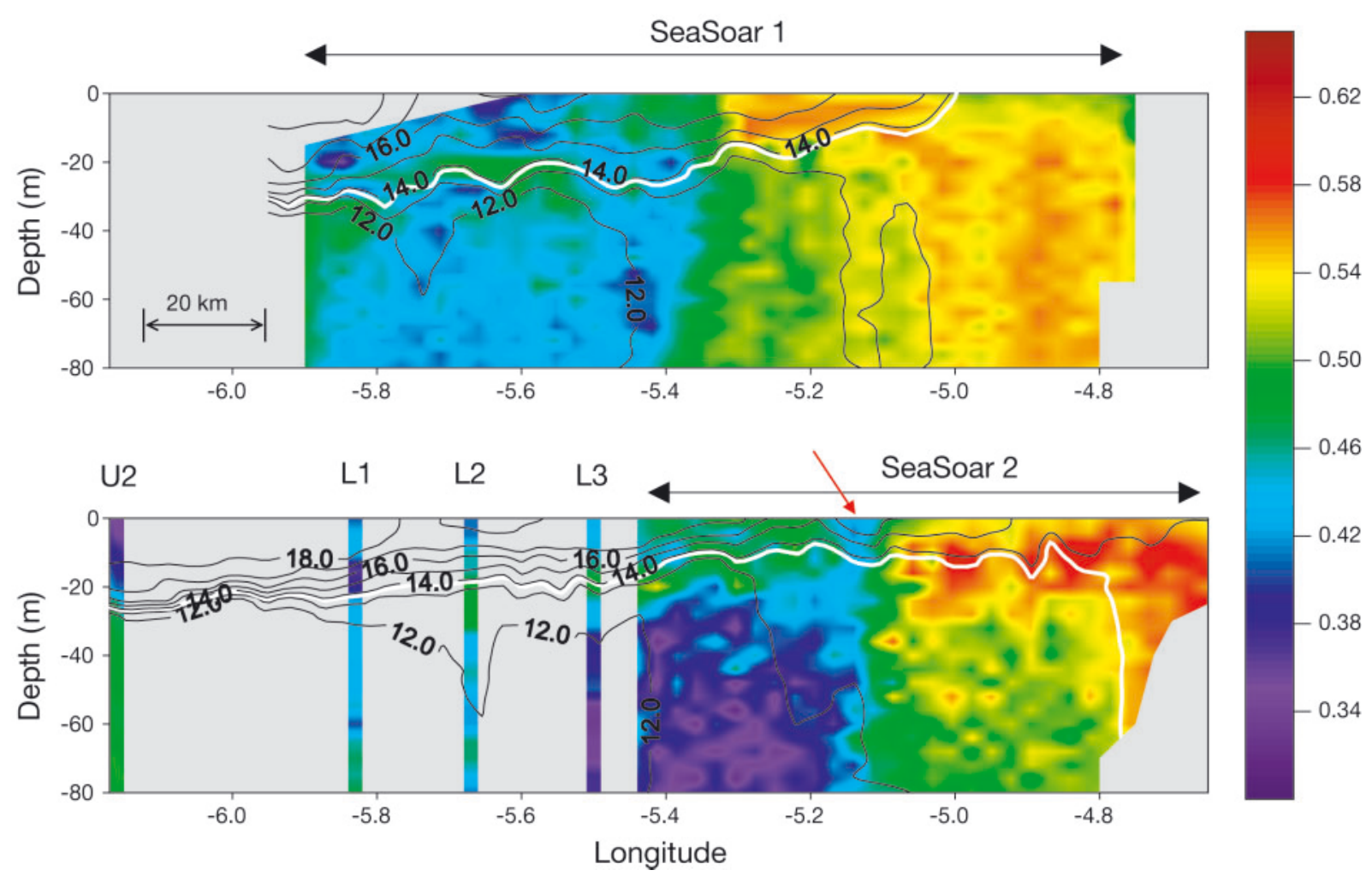

Fig. 5. Frontal cross-sections of $F_{\mathrm{v}} / F_{\mathrm{m}}$ and temperature $\left({ }^{\circ} \mathrm{C}\right)$ following spring (top graph, 2 August 1999) and neap (bottom graph, 8 to 9 August 1999) tidal conditions. Black lines are isotherms contoured every $1^{\circ} \mathrm{C}$ from 12 to $18^{\circ} \mathrm{C} ; 13.7^{\circ} \mathrm{C}$ isotherm is also contoured in white to highlight adjustment of frontal position. Data were collected using SeaSoar undulating tow-body during 2 cross-frontal transects on a line from Stns M to U2 on 2 and 8 August and from overnight CTD survey on 9 August. Horizontal resolution of SeaSoar data is $\sim 1 \mathrm{~km}$. Red arrow indicates position of a local minimum in $F_{\mathrm{v}} / F_{\mathrm{m}}$ associated with a small frontal eddy or filament

direct evidence that changes in phytoplankton physiology occur as a result of the fortnightly tidal cycle.

The higher resolution of the data collected with the towed instrument also revealed smaller scale physiological differences, associated with physical variability. An example was a region of lower photochemical efficiency in the surface around $5.14^{\circ} \mathrm{W}$ during the second SeaSoar run, which was associated with relatively warm surface water (Fig. 5b). This feature probably marked a filament or eddy structure on the frontal boundary, within which warm surface water and a phytoplankton population with a lower photochemical efficiency was being entrained. Such eddy structures are considered to be important for the cross-frontal transfer of nutrients (Pingree 1979).

Values of $\sigma_{\text {PSII }}$ were significantly different between the stratified and mixed regions of the front (Fig. 2d). The highest values around $750 \AA^{2}$ quanta $^{-1}$ were found within and above the thermocline at Stn U2, with lower values of $\sigma_{\text {PSII }}$ towards the mixed side. A distinct minimum in $\sigma_{\mathrm{PSII}}$ was apparent within the deep population in the frontal region at around $5.4^{\circ} \mathrm{W}$ during the crossfrontal CTD survey (Fig. 2d).
The patterns of physiological variability contrasted with those described by Kolber et al. (1990) for a front in the Gulf of Maine. These authors reported relatively low values of $F_{\mathrm{v}} / F_{\mathrm{m}}$ and higher values of $\sigma_{\mathrm{PSII}}$ towards the mixed side of the front, which were interpreted as indicative of a poorly developed photosynthetic apparatus under conditions of low mean irradiance. In the current study, prolonged high irradiance was likely to have been experienced by a proportion of the in situ population at some stage in the previous $14 \mathrm{~d}$ due to the spring-neap stratification cycle within the frontal transition region. Additionally, the mean irradiance experienced was likely to have remained relatively high (see above).

\section{Effect of vertical mixing on variations in physiological parameters}

Diel variations in both $F_{\mathrm{q}}{ }^{\prime} / F_{\mathrm{m}}{ }^{\prime}$ and $\sigma_{\mathrm{PSII}}{ }^{\prime}$ were observed in the $25 \mathrm{~h}$ time-series obtained at all the fixed stations. Both parameters declined during the day and displayed minima associated with the peak irradiance 
around midday. Maximal reductions in $F_{\mathrm{q}}{ }^{\prime} / F_{\mathrm{m}}{ }^{\prime}$ ranged from $60 \%$ in the surface at Stns U2 and M during neap tides (M2), to $45 \%$ during springs at this station (M3). Reductions in $F_{\mathrm{q}}{ }^{\prime} / F_{\mathrm{m}}{ }^{\prime}$ during a generally cloudy day at Stn $\mathrm{E}$ were around $35 \%$ at peak surface irradiances. At Stn U2, $\sigma_{\text {PSII }}$ ' was around $50 \%$ lower at midday irradiances than during the dark, whereas reductions of around $30 \%$ were observed for M2, M3 and E.

The vertical distribution of $\sigma_{\text {PSII }}$ ' within a water column will depend on the relative magnitudes of the vertical mixing rate and the rates at which phytoplankton alter $\sigma_{\text {PSII }}$ in response to changing irradiance (Falkowski 1983, Lewis et al. 1984a, Kolber et al. 1990). If mixing causes cells to be moved through the vertical light gradient faster than they can alter their photosynthetic apparatus, the distribution will tend to be uniform with depth. Conversely, if the acclimation rate is faster than the mixing rate, cells will tend to become acclimated to the light regime leading to vertical heterogeneity in this parameter.

Microstructure measurements with FLY provided a measure of vertical mixing rates at 3 of the fixed $25 \mathrm{~h}$ stations. Mean profiles of $\sigma_{\mathrm{PSII}}$ at these 3 stations showed significantly different vertical gradients, with a decrease from U2 to M2 to M3 in accordance with increasing vertical mixing (Fig. 6a). Lewis et al. (1984a), derived an equation relating the rate of change of an observed parameter to the rate of vertical mixing, which was tested by measuring the vertical variability in the maximum rate of chlorophyll specific production $\left(P_{\max }^{*}\right)$ and the rate of turbulent dissipation $(\varepsilon)$ within the water column by Lewis et al. (1984b). A similar analysis of the current data set showed an approximately hyperbolic relationship between $\varepsilon$ and the vertical gradient of $\sigma_{\text {PSII }}$ ' within the upper water column that was qualitatively very similar to the model predictions and results of Lewis et al. (1984a,b) (Fig. 6b).

\section{Relationships between fluorescence and ${ }^{14} \mathrm{C}$-derived physiological parameters}

Maximum quantum yields for carbon fixation $\left(\phi_{\mathrm{C}, \max }\right)$ were highest within the nutrient-replete, mixed regions (Fig. 7a), approaching the assumed near-maximal values of $0.08 \mathrm{~mol} \mathrm{C}$ (mol photon) ${ }^{-1}$ (Myers 1980, Babin et al. 1996). Lower values of $\phi_{C, \max }$ were calculated for the more stratified regions and were associated with the lower maximum photochemical quantum yields $\left(F_{\mathrm{v}} / F_{\mathrm{m}}\right)$ measured in these regions (Fig. 7a). Changes in photochemical quantum yields and hence the proportion of functional reaction centres, $f$ (Geider et al. 1993, Kolber \& Falkowski 1993, Babin et al. 1996), accounted for around $44 \%$ of the variance in $\phi_{\mathrm{C}, \max }$ (Fig. $7 \mathrm{a}$ ).

The relationship between $F_{\mathrm{v}} / F_{\mathrm{m}}$ and nitrate suggested that $f$ only became significantly reduced at the very low (undetectable) ambient nitrate concentrations encountered on the stratified side of the front (Fig. 7b).
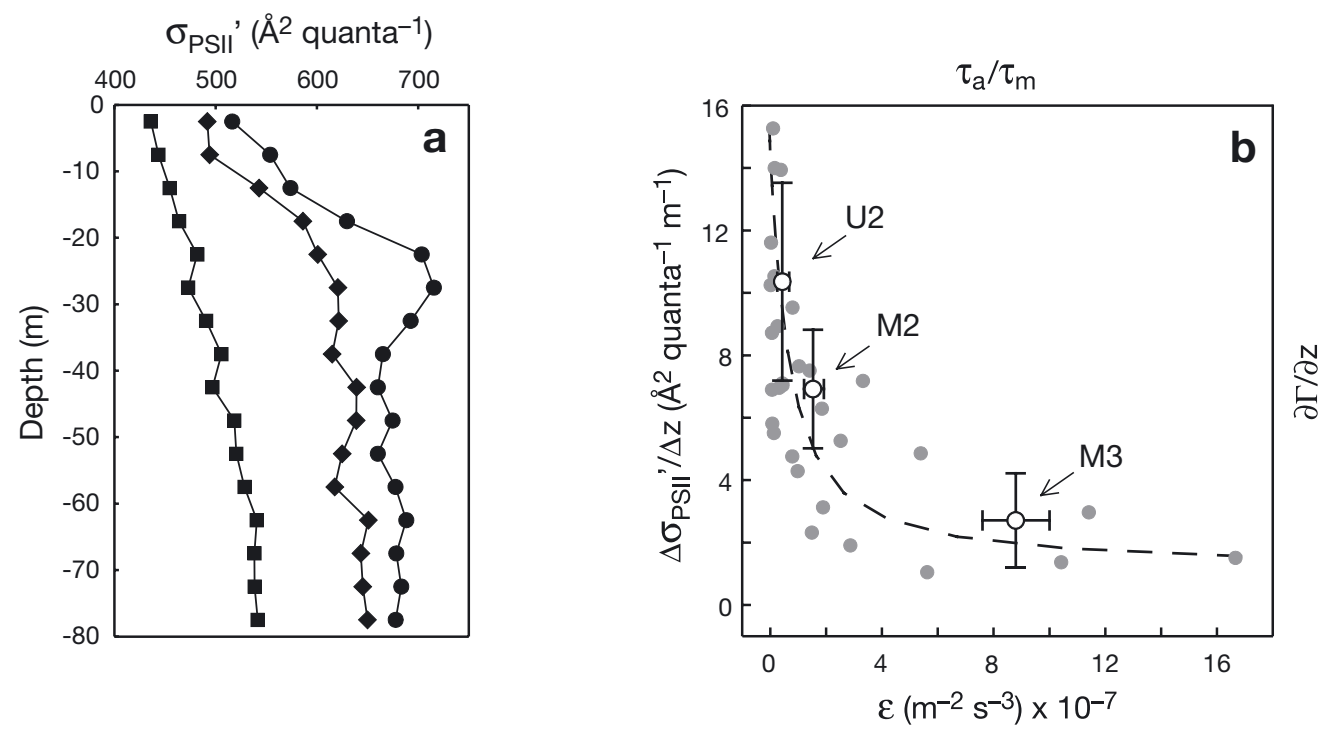

Fig. 6. Photoacclimation and mixing as controls on $\sigma_{\mathrm{PSII}}{ }^{\prime}$. (a) Daytime mean vertical profiles of $\sigma_{\mathrm{PSII}}$ ' for the 3 stations where observations with FLY profiler were collected; $(\bullet)$ U2, $\bullet$ M2, (®) M3. (b) Vertical gradient in $\sigma_{\text {PSII }}$ for upper portion of water column $(<30 \mathrm{~m})$ against rate of dissipation of turbulent kinetic energy $(\varepsilon)$ during daytime at the 3 stations; 0 : mean values calculated for the 3 stations, vertical error bars are \pm 1 SD horizontal error bars are approximate $95 \%$ confidence intervals of mean dissipation estimated by bootstrapping technique (Effron \& Gong 1993). ๑: individual values of depth mean $\varepsilon$ vs $\Delta \sigma_{\mathrm{PSII}}{ }^{\prime} / \Delta \mathrm{z}$ for all the FLY - CTD/FRRF pairs collected at the 3 stations; dotted line is normalised solution of a photoacclimation-diffusion equation (Lewis et al. 1984a), showing expected relationship between vertical variability in any photoadaptive parameter $(\Gamma)$ and ratio of photoacclimation rate to vertical mixing rate $\left(\tau_{\mathrm{a}} / \tau_{\mathrm{m}}\right)$ 

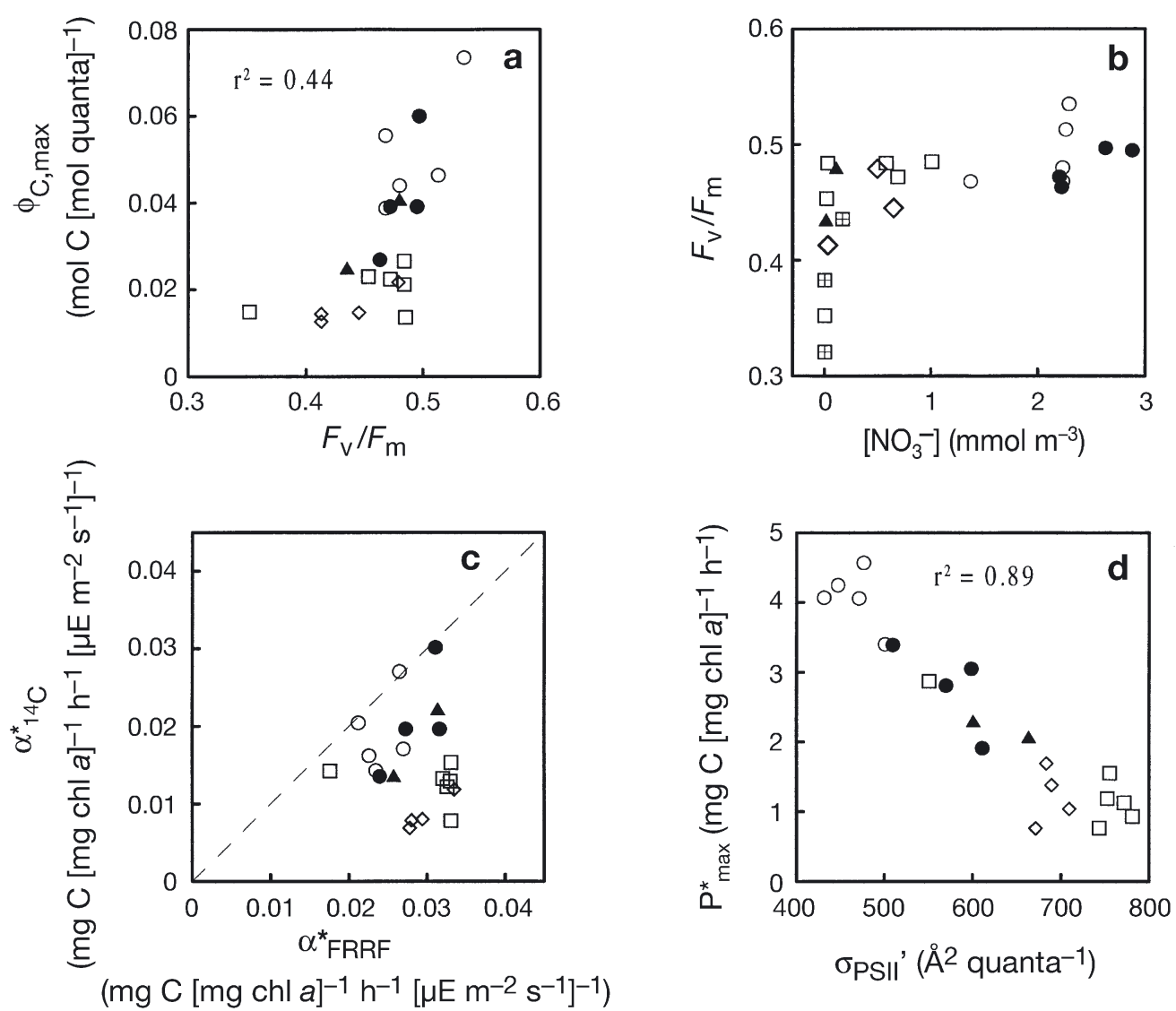

Fig. 7. ${ }^{14} \mathrm{C}$-derived physiological parameters from $P^{*}$ vs $E$ experiments vs FRRF-derived parameters and environmental conditions. (a) ${ }^{14} \mathrm{C}$-derived $\phi_{\mathrm{C} \text {,max }}$ as a function of FRRF-derived $F_{\mathrm{v}} / F_{\mathrm{m} i}$ FRRF measurements from mean nighttime values from the station and sample depth for which the water was collected. (b) $F_{\mathrm{v}} / F_{\mathrm{m}}$ as a function of ambient nitrate concentration. (c) $\alpha^{*}{ }_{14} \mathrm{C}$ as a function of $\alpha_{\text {FRRF. (d) }}^{*}{ }^{14} \mathrm{C}$-derived $P^{*}{ }_{\text {max }}$ as a function of FRRF-measured $\sigma_{\text {PSII }}$. Symbol types for all plots correspond to stations: $(\square) \mathrm{U} 2,(\diamond) \mathrm{E},(\mathbf{\Delta}) \mathrm{L} 3,(\bullet) \mathrm{M} 2,(\mathrm{O}) \mathrm{M} 3$. Percentage variance explained by linear regressions between parameters (where significant) is indicated on plots $(\mathrm{n}=21, \mathrm{p}<0.001$ for all). Additional data collected at U2 site $(\mathbb{\boxplus})$ is included in (b) to clarify relationship at low nitrate concentrations

Lower $\phi_{\mathrm{C}, \max }$ within the stratified regions was also associated with lower nutrient concentrations, $55 \%$ of the variance in $\phi_{\mathrm{C}, \max }$ being explained by regression against the ambient nutrient concentration (data not shown). Any reduction in $f$ must reduce $\phi_{\mathrm{C}, \max }$ (Babin et al. 1996). The data therefore suggested that nutrient limitation reduced the maximal photochemical quantum efficiency and hence the efficiency of carbon fixation on the stratified side of the front. However much of the reduction in $\phi_{\mathrm{C}, \max }$ occurred at relatively high ambient nitrate concentrations $(\sim 1 \mathrm{mmol})$, and the range of variability in $F_{\mathrm{v}} / F_{\mathrm{m}}$ (2-fold) was insufficient to explain the $\sim 6$-fold variation in $\phi_{\mathrm{C} \text {, max }}$. Thus, as found by Babin et al. (1996), other factors, such as a higher proportion of non-photosynthetic pigments, must also have been responsible for some of the reduction in $\phi_{C, \max }$ as the nitrate concentration decreased. Absorption by nonphotosynthetic pigments may also have accounted for some of the unexplained variance in Fig. 7a. Unfortu- nately, sampling for HPLC analyses was not performed as frequently as sampling for $P^{*}$ vs $E$ and $a^{*}$ measurements, so that any comparable changes in the ratios of non-photosynthetic to photosynthetic pigments could not be resolved.

FRRF-based estimates of the maximum light utilisation efficiency ( $\left.\alpha^{*}{ }_{\text {FRRF }}\right)$ were initially calculated using Eq. (1), assuming a constant PQ value of 1.4 (Laws 1991) and a constant ratio of $0.002 \mathrm{~mol}$ PSII (mol chl a) ${ }^{-1}$ (Kolber \& Falkowski 1993). Although the relative magnitudes of both FRRF- and ${ }^{14} \mathrm{C}$ - derived $\alpha^{*}$ estimates were comparable, no clear trend was observed for the complete data set (Fig. 7c). FRRF-derived values of $\alpha^{*}$ were higher than ${ }^{14} \mathrm{C}$-derived values at all the stations, and much higher for the thermocline at the highly stratified U2 site and the stratified E site (Fig. 7c). Absolute values for the remaining regions were similar, with a weakly significant correlation observed between the 2 methods $\left(\mathrm{r}^{2}=0.34, \mathrm{n}=12, \mathrm{p}<0.05\right)$. 
It was possible that $P^{*}$, and hence $\alpha^{*}$, were underestimated by the ${ }^{14} \mathrm{C}$ method at Stn $\mathrm{E}$ and the thermocline of Stn U2 due to 'bottle effects' and differences between the ambient and incubation temperatures. Additionally, the manipulation and enclosure of the dense and virtually monospecific community of coccolithophores found within the thermocline at U2 (Sharples et al. 2001), may have resulted in artefacts being introduced into ${ }^{14} \mathrm{C}$-derived physiological values.

The observed relationships between $F_{\mathrm{q}}{ }^{\prime} / F_{\mathrm{m}}{ }^{\prime}, \sigma_{\mathrm{PSII}}$ and irradiance for the $25 \mathrm{~h}$ time-series stations could have been used to calculate electron transport rates for the fixed stations and subsequently to model carbon fixation (e.g. Kolber \& Falkowski 1993, Suggett et al. 2001). However, the relationship of electron transport rates to both oxygen evolution and carbon fixation can vary, particularly for irradiances above light saturation (e.g. Flameling \& Kromkamp 1998). Additionally this approach could not be used to convert the cross-frontal FRRF data (cf. Figs. $2 \& 5$ ) to productivity estimates, as the transects were performed at night. Further investigation of the relationships between FRRF- and ${ }^{14} \mathrm{C}$ derived physiological parameters revealed a striking and highly significant $\left(\mathrm{r}^{2}=0.89, \mathrm{p}<0.001, \mathrm{n}=21\right)$ negative correlation between the ${ }^{14} \mathrm{C}$ derived value of $P^{*}{ }_{\text {max }}$ and $\sigma_{\text {PSII }}{ }^{\prime}$ (Fig. $7 \mathrm{~d}$ ), a similar relationship being found between $P^{*}{ }_{\text {max }}$ and $\sigma_{\text {PSII }}$ from night-time casts at the same site (data not shown: $\mathrm{r}^{2}=0.68, \mathrm{p}<0.001$, $\mathrm{n}=21$ ). Highest values of $P^{*}{ }_{\max }$ and lowest values of $\sigma_{\text {PSII }}$ (and $\sigma_{\text {PSII }}$ ) were found towards the nutrientreplete mixed side of the front (Fig. $7 \mathrm{~d}$ ). Values of $P^{*}$ max decreased towards the nutrient-depleted stratified regions, with the lowest values of $P^{*}{ }_{\max }$ and highest values of $\sigma_{\text {PSII }}$ being found within the thermocline at Stn U2 (Fig. 7d).

\section{Comparisons between modelled and ${ }^{14} \mathrm{C}$ derived productivity}

An empirical model was developed to examine how the observed physiological variability may have driven changes in primary production rates across the frontal system. It is emphasised that the derived model was used simply as a means for exploration of the current data set and is unlikely to have wider applicability. The value of $\alpha^{*}$ could be calculated for each FRRF data point using Eq. (1), while the value of $P^{*}$ max was extrapolated using the empirical relationship with $\sigma_{\mathrm{PSII}}\left(P^{*}{ }_{\max }=8.7( \pm 0.5)-\right.$ $\left.0.0103( \pm 0.0008) \sigma_{\text {PSII }}\right)$ (Fig. 7d). The productivity could then be calculated from the FRRF data using the model outputs for $\alpha^{*}$ and $P^{*}$ max and the instantaneous irradiance $(E)$. Mod- elled and ${ }^{14} \mathrm{C}$-derived production rates for the $P^{*}$ vs $E$ data set were highly correlated, with $92 \%$ (93\% after logarithmic transformation) of the variance in ${ }^{14} \mathrm{C}$-based productivity rates explained using the model applied to FRRF data (Fig. 8). At high irradiances (i.e. above $E_{\mathrm{k}}$ ) this is not surprising, as the empirical nature of the model forces the 2 techniques to agree. FRRFmodelled productivity was higher than ${ }^{14} \mathrm{C}$-based estimates at low irradiances as a result of the higher values of $\alpha_{\text {FRRF }}^{*}$ estimated using Eq. (1) (Fig. 7c). Overall, a strong correlation between the FRRF- and ${ }^{14} \mathrm{C}$-based estimates (Fig. 8), despite considerable differences in $\alpha^{*}$ estimates (Fig. 7c), indicated the importance of irradiance and $P^{*}{ }_{\max }$ in governing productivity.

Daily integrated production using the model applied to FRRF data obtained at the 4 fixed stations was also comparable to the productivity estimated using the ${ }^{14} \mathrm{C}$ simulated in situ experiments at these sites (Table 2). The range of productivity estimates from both the simulated in situ and FRRF-modelled productivity were similar to previous values from the region (Holli-

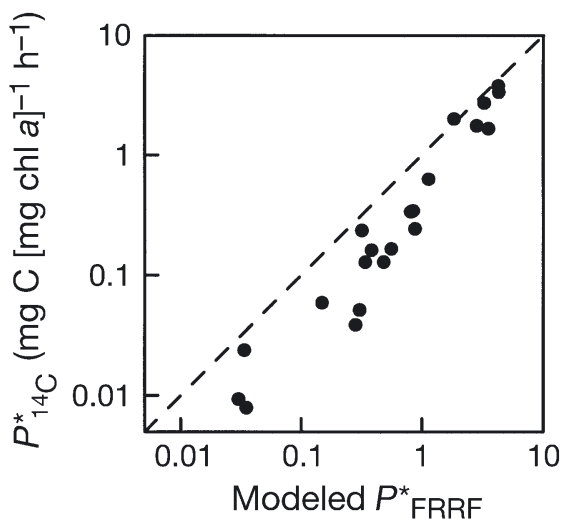

Fig. 8. Relationship between productivity estimates derived from ${ }^{14} \mathrm{C} P^{*}$ vs $E$ experiments and empirical model applied to FRRF data. Values calculated using in situ irradiance at time of sampling, $\mathrm{PQ}=1.4$ and $0.002 \mathrm{~mol}$ PSII (mol chl a) ${ }^{-1}$ (Eq. 1). Empirical model applied to FRRF data explained $92 \%$ of variance in ${ }^{14} \mathrm{C}$-derived productivity $(93 \%$ after logarithmic transformation)

Table 2. Comparison of estimated productivity at fixed stations using simulated in situ ${ }^{14} \mathrm{C}$ and empirical model applied to FRRF data

\begin{tabular}{|c|c|c|c|c|}
\hline Method & $\begin{array}{c}\mathrm{U} 2 \\
\text { (stratified) }\end{array}$ & $\begin{array}{c}\mathrm{E} \\
\text { (stratified) }\end{array}$ & $\begin{array}{c}\text { M2 } \\
\text { (mixed neaps) }\end{array}$ & $\begin{array}{c}\mathrm{M} 3 \\
\text { (mixed springs) }\end{array}$ \\
\hline \multicolumn{5}{|c|}{ Production (g C m $\mathbf{~ m}^{-2} \mathrm{~d}^{-1}$ ) } \\
\hline${ }^{14} \mathrm{C}$ & 0.77 & 0.48 & 1.3 & 0.91 \\
\hline FRRF & 0.70 & 0.51 & 1.9 & 1.4 \\
\hline \multicolumn{5}{|c|}{ Specific production (g C $[\text { g chl } a]^{-1} d^{-1}$ ) } \\
\hline${ }^{14} \mathrm{C}$ & 6.3 & 10 & 19 & 13 \\
\hline FRRF & 6.7 & 10 & 24 & 15 \\
\hline
\end{tabular}


gan et al. 1984, Videau 1987). Integrated daily productivity when normalised to depth-integrated chlorophyll concentrations for the 4 sites was also comparable using the 2 techniques (Table 2). Calculated specific production was lower at the 2 stratified sites (U2 \& E) than at Stn $M$ using both techniques (Table 2). A slightly lower rate for the M3 as opposed to the M2 site was also calculated.

\section{Modelled production from SeaSoar data}

Integrated daily production across the frontal region was estimated from the SeaSoar data using the empirical model. Such an extrapolation is dependent on the relationship observed at the fixed sites (Fig. 7d), being valid for the time and space domain over which the SeaSoar data were acquired. Although there is no clear physiological explanation for the relationship between $P^{*}{ }_{\max }$ and $\sigma_{\mathrm{PSII}}$ (see 'Discussion'), the presence of data throughout the environmental gradients of the frontal region lends support to the modelling exercise (Fig. 7d). In particular, the front represents a gradient in mixing/stratification, with the U2 (highly stratified) and M3 (mixed) sites characterising the end points for the modelled domain and Stns E, L3, and M2 spanning a range of intermediate mixing. The data obtained at these stations displayed a linear relationship along the stratification gradient, providing a basis for extrapolation (Fig. 7d).

The data were averaged into vertical profiles with approximately $3 \mathrm{~km}$ horizontal resolution, and values of $\alpha^{*}$ and $P_{\text {max }}^{*}$ were estimated as described in the previous section. The diel cycle of irradiance just beneath the sea surface was modelled at 30 min intervals for a $24 \mathrm{~h}$ period using a simple sinusoidal relationship, with a midday maximum of $1300 \mu \mathrm{mol}$ photons $\mathrm{m}^{-2} \mathrm{~s}^{-1}$. The depth-resolved distribution of chlorophyll across the front was then estimated from the calibrated FRRF $F_{\mathrm{m}}$ measurements, while light penetration through the water column was modelled using a chlorophylldependent $K_{\mathrm{d}}$, i.e. $K_{\mathrm{d}}=0.082+0.025 \mathrm{chl}$ a (Fig. 4).

Cross-frontal transects of the depth-integrated daily productivity using this model indicated small-scale variability, linked to observed changes in surface temperature that would not be resolvable from observations at fixed stations (Fig. 9). Higher productivity towards the stratified side of the front (around 5.1 to $5.5^{\circ} \mathrm{W}$ ) was calculated from the data collected following spring tide conditions and was associated with the suggested increase in the maximal photosynthetic rate in this region (Fig. 9b,d). Conversely, higher production toward the mixed side of the front (around $4.75^{\circ} \mathrm{W}$ ) following neap tides was largely associated with the accumulation of biomass in this region, the maximal photosynthetic rates being lower (Fig. 9b,c,d). Measured values of $P^{*}{ }_{\max }$ generated from the ${ }^{14} \mathrm{C} P^{*}$ vs $E$ experiments and the daily productivity calculated from the ${ }^{14} \mathrm{C}$ simulated in situ experiments, provide limited confirmation of the variations in productivity predicted by the empirical model applied to the SeaSoar data (Fig. 9c,d).
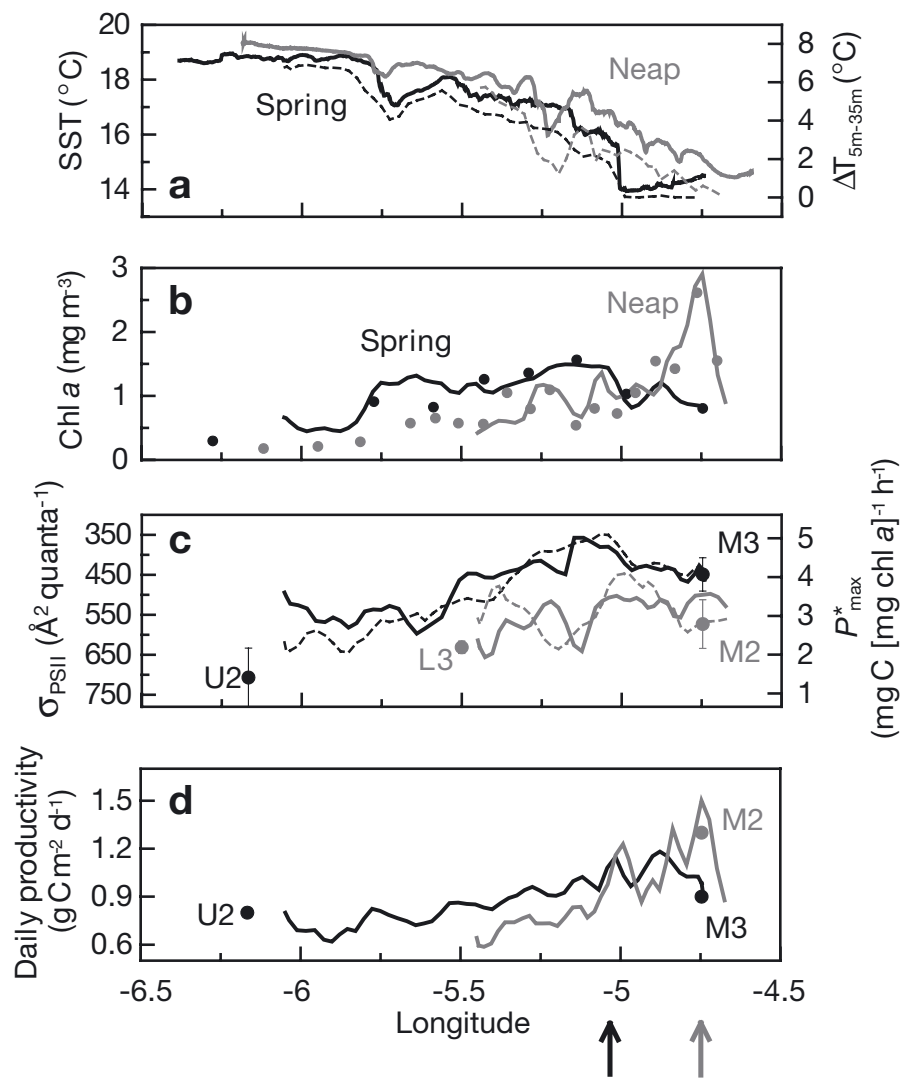

Fig. 9. Results of empirical productivity model applied to cross-frontal FRRF data obtained using SeaSoar undulator during 2 crossings of front following spring (black lines and symbols 2 August 1999) and neap (grey lines and symbols 8 to 9 August 1999) tidal conditions. (a) Sea-surface temperature $\left({ }^{\circ} \mathrm{C}\right.$, continuous lines) measured from ship's underway system, and temperature difference (dotted lines) from 5 to $35 \mathrm{~m}$ $\left(\Delta \mathrm{T}_{5 \mathrm{~m}-35 \mathrm{~m}}{ }^{\circ} \mathrm{C}\right)$ calculated from SeaSoar data. (b) Sea-surface chlorophyll a distribution from calibrated FRRF $F_{\mathrm{m}}$ measurements (lines) and from samples collected underway (symbols). (c) Distribution of $\sigma_{\text {PSII }}$ and $P^{*}{ }_{\text {max }}$ across frontal region; continuous lines: surface (mean 0 to $5 \mathrm{~m}$ ) $\sigma_{\text {PSII }}$ dotted lines: sub-surface (mean 25 to $30 \mathrm{~m}$ ) $\sigma_{\mathrm{PSII}}$ from FRRF on SeaSoar; symbols show $P^{*}{ }_{\max }$ (mean $\pm \mathrm{SD}$ ) from all ${ }^{14} \mathrm{C} P^{*}$ vs $E$ experiments at U2, M2, M3 and L3 sites; note inverted scale for $\sigma_{\mathrm{PSII}}$ (left axis), to enable values of $\sigma_{\mathrm{PSII}}$ to conform with values of $P^{*}{ }_{\max }$ (right axis) (i.e. using relationship in Fig. 7d). (d) Depthintegrated daily production $\left(\mathrm{g} \mathrm{C} \mathrm{m}^{-2} \mathrm{~d}^{-1}\right.$ ) calculated by applying empirical model to FRRF data and estimated using simulated in situ ${ }^{14} \mathrm{C}$ experiments at the 3 stations occupied for $25 \mathrm{~h}$ in vicinity of front: U2, M2 (neap) and M3 (spring); note that station data is not concurrent with SeaSoar data. Arrows indicate approximate frontal position, defined as point at which $15^{\circ} \mathrm{C}$ isotherm outcropped at surface 


\section{DISCUSSION}

\section{Physiological variability $1: \phi_{\mathrm{C}, \max }$ and $\alpha^{*}$}

The high degree of coherence between the physical structure of the front and the spatial variations in the photochemical efficiency $\left(F_{\mathrm{v}} / F_{\mathrm{m}}\right)$ indicated that physical processes strongly affect the physiological state and growth of phytoplankton in frontal regions (Figs. 2 \& 5). Lower $F_{\mathrm{v}} / F_{\mathrm{m}}$ values towards the stratified side of the front (Figs. 2, 5 \& 7b) were consistent with a reduction in the fraction of functional PSII reaction centres under conditions of nutrient stress (e.g. Kolber et al. 1990, Falkowski 1992, Geider et al. 1993, Parkhill et al. 2001). Independent estimates of $\phi_{C, \max }$ further supported this hypothesis and indicated that carbon fixation on the stratified side of the front was limited by the availability of inorganic nutrients (Fig. 7a,b).

No clear relationship between $\alpha^{*}{ }_{\text {FRRF }}$ and $\alpha^{*}{ }_{14 C}$ was found in the current study (Fig. 7c). Boyd et al. (1997) previously found significant correlations between $F_{\mathrm{v}} / F_{\mathrm{m}}$ and ${ }^{14} \mathrm{C}$-based $\alpha^{*}$, but no significant relationship between fluorescence and ${ }^{14} \mathrm{C}$-based $\alpha^{*}$. Suggett et al. (2001) found values of FRRF-derived $\alpha^{*}$ which were around 1.5 to 2.5 times higher than ${ }^{14} \mathrm{C}$-derived values. Both of these earlier studies used vertical profiles of fluorescence parameters and calculated electron transport rates in order to derive fluorescence-based $P^{*}$ vs $E$ curves and hence estimate $\alpha^{*}{ }_{\text {FRRF }}$, rather than the direct calculation expressed in Eq. (1) of the present study.

Higher values for $\alpha^{*}$ from the FRRF technique (Eq. 1, Fig. $7 \mathrm{c}$ ) are expected for a number of reasons (for a more detailed discussion see Flameling \& Kromkamp 1998 and Suggett et al. 2001). The FRRF technique measures gross ETR, while the ${ }^{14} \mathrm{C}$ technique, even for short duration incubations, approximates net carbon fixation (Williams et al. 1996, Marra 2002). Phytoplankton respiration may therefore account for some of the discrepancy (around 10\%) between values of $\alpha^{*}{ }_{\text {FRRF }}$ and $\alpha^{*}{ }_{14 \mathrm{C}}$ (Grande et al. 1989, Daneri et al. 1992, Suggett et al. 2001). Processes such as cyclic electron flow around PSII (Falkowski et al. 1986, Prášil et al. 1996), photorespiration (Raven \& Johnston 1991) and the Mehler reaction (Kana 1992), will de-couple the ETR from carbon fixation and lead to higher $\alpha^{*}{ }_{\text {FRRF }}$ as opposed to $\alpha^{*}{ }_{14} \mathrm{C}$. The use of reductant for processes other than carbon fixation will also de-couple the ETR from carbon fixation and will result in a higher PQ value (Eq. 1).

The differences between $\alpha^{*}{ }_{\text {FRRF }}$ and $\alpha^{*}{ }_{14 C}$ between sites could therefore reflect variability in one or more of these processes (Fig. $7 \mathrm{c}$ ). The factor of 2 to 3 required to explain the observations from the more stratified sites (Fig. 7c) was comparable to values pre- viously reported for combined $\mathrm{O}_{2}$ and ${ }^{14} \mathrm{C}$ incubation experiments in the region of the current study (Holligan et al. 1984), and presumably represented the combined effects of the processes mentioned above.

\section{Physiological variability 2: $\sigma_{\mathrm{PSII}}$ and $\boldsymbol{P}_{\text {max }}^{*}$}

Observations of the functional absorption cross section $\left(\sigma_{\mathrm{PSII}}\right)$ are more difficult to interpret than observations of $F_{\mathrm{v}} / F_{\mathrm{m}}$, as $\sigma_{\mathrm{PSII}}$ depends on both the light history and the nutrient status of the cells as well as displaying species-specific variability (Kolber et al. 1988, 1990, Falkowski 1992). Higher values of $\sigma_{\text {PSII }}$ towards the stratified regions (Figs. 2d \& 7d) were consistent with a number of studies that have shown increases in $\sigma_{\mathrm{PSII}}$ following nutrient limitation (Kolber et al. 1988, Herzig \& Falkowski 1989, Berges et al. 1996). However, species-dependent variations in $\sigma_{\mathrm{PSII}}$ across the frontal region cannot be discounted. In particular, lower values of $\sigma_{\mathrm{PSII}}$ were generally observed in regions dominated by diatom populations, while higher values of $\sigma_{\mathrm{PSII}}$ were found for coccolithophore populations. Such a pattern is consistent with the currently limited data available on taxon-specific variability in $\sigma_{\text {PSII }}$ (Olson et al. 1996).

Variations in $\sigma_{\mathrm{PSII}}$ (or $\sigma_{\mathrm{PSII}}$ ) as a function of the irradiance experienced are likely to reflect a variety of different processes (acting over different time-scales) which phytoplankton can employ to alter absorption. The observed diel variability in $\sigma_{\text {PSII }}$ ' was likely to be a result of non-photochemical quenching (NPQ) processes, which have characteristic relaxation times in the order of tens of minutes (Kolber \& Falkowski 1993). NPQ has been observed to reduce $\sigma_{\text {PSII }}$ by up to $50 \%$ during the day (Falkowski et al. 1994, Olaizola et al. 1994, Vassiliev et al. 1994), which is comparable to the 30 to $50 \%$ reductions observed during the 4 timeseries stations in the present study. Over longer timescales, photoacclimation to the mean daily irradiance has been observed to cause up to 3-fold changes in $\sigma_{\text {PSII }}$ (Ley \& Mauzerall 1982, Kolber et al. 1988). Longer time-scale photoacclimation may well have been a factor affecting the observed distribution of $\sigma_{\mathrm{PSII}}$ and $\sigma_{\mathrm{PSII}}$ '. However, interpretation is confounded due to the variations in nutritional status and species composition of the phytoplankton communities.

The observed vertical distribution of $\sigma_{\mathrm{PSII}}$ as a function of both short-term (NPQ) and long-term (photoacclimation) responses to light was also affected by the vertical mixing rate (e.g. Falkowski 1983, Lewis et al. $1984 \mathrm{a}, \mathrm{b})$. The combined data on $\sigma_{\mathrm{PSII}}{ }^{\prime}$ and $\varepsilon$ represent one of the few examples of a photoacclimation model being tested against a relatively direct estimate of vertical mixing rates $(\varepsilon)$ and, to our knowledge, the first in 
tidally dominated waters (Fig. 6b). The results indicate that phytoplankton were not able to adjust their photosynthetic apparatus to the instantaneous light level within the mixed region of the front, as the mixing time-scale was faster than the acclimation time-scale (Fig. 6b). Thus, deep mixing may exert a control on production by reducing the potential for individual cells to fully exploit the periods of high light, irrespective of the relatively high integrated daily irradiance experienced within the mixed water column. Such a conjecture requires testing against a combined mixing-photoacclimation-production model. A model formulated in terms of fluorescence-derived parameters could be tested against FRRF field measurements and would provide a means of assessing the degree of light limitation within fully mixed water columns or deep mixed layers.

The strong negative correlation between $\sigma_{\text {PSII }}\left(\sigma_{\text {PSII }}\right)$ and $P^{*}$ max observed in the current study (Fig. $7 \mathrm{~d}$ ), was unlikely to represent a causal relationship. Rather the 2 parameters may have independently varied as a result of physiological and/or taxonomic responses to changing environmental conditions across the frontal region. $P^{*}{ }_{\max }$ is the product of the number of functional PSII reaction centres normalised to chlorophyll $a$ and their maximum turnover rate $\left(1 / \tau_{\mathrm{PSII}}\right)$, (Falkowski 1992), i.e.

$$
P_{\text {max }}^{*}=\frac{f \text { PSII: } \mathrm{chl}}{\tau_{\mathrm{PSII}}}
$$

Combining Eqs. (1) \& (2), a negative correlation between $P^{*}$ max and $\sigma_{\text {PSII }}$ (or more specifically a positive correlation between $P^{*}$ max and the reciprocal of $\sigma_{\text {PSII }}$ ) might therefore be expected if the ratio of $\alpha^{*}: \tau_{\text {PSII }}$ remains constant. However, this cannot provide a mechanistic model for the data in Fig. $7 d$, as $\alpha^{*}$ and $\sigma_{\text {PSII }}$ are not independent parameters. Indeed, at light saturation, photosynthesis is limited by reactions downstream of PSII and $P^{*}$ max is expected to be independent of $\sigma_{\text {PSII }}$ (Sukenik et al. 1987, Falkowski \& Raven 1997).

Following the ideas of Behrenfeld \& Falkowski (1997), a more ecophysiological explanation for the relationship in (Fig. 7d) can be formulated. It is suggested that variations in resource availability (i.e. nutrients and light) across the frontal region set limits on $P^{*}{ }_{\text {max }}$ at any location. Once set, the maximal achievable photosynthetic rate dictates the requirement for electron transport through PSII. The range of irradiances experienced at a location (cf. Fig. 6), combined with the demand for electrons from PSII will, in turn, define the required light-harvesting capacity as signified by $\sigma_{\text {PSII }}$. Thus, it seems reasonable that the continuous gradient in physical forcing, and hence environmental conditions across the front, results in a gradient in maximal achievable carbon fixation rate while simultaneously setting the strategy for light-harvesting in order to achieve this rate. As such, the relationship in Fig. 7d may define a solution for growth optimisation within the specific system studied, which is only revealed due to the constrained way in which the environment changes across the front.

In summary, whether $P^{*}{ }_{\max }$ and $\sigma_{\mathrm{PSII}}$ were varying independently or as a result of some common physiological/ecological mechanism, could not be assessed from the current data set. However, it is suggested that the observed physiological gradients resulted from shifts in the balance between light-harvesting and carbon fixation across the frontal system. Future extension of resource-balance models which mechanistically describe the effect of environmental changes on $P^{*}{ }_{\max }$ (e.g. Geider et al. 1998) to include $\sigma_{\text {PSII }}$ would aid in our understanding of how phytoplankton physiology and growth is controlled in the vicinity of tidal mixing fronts.

Regardless of the underlying cause, a relationship between $\sigma_{\mathrm{PSII}}\left(\sigma_{\mathrm{PSII}}{ }^{\prime}\right)$ and $P^{*}{ }_{\max }$ has a number of implications. Firstly, our observations of the vertical variability of $\sigma_{\text {PSII }}$ ' under conditions of differing vertical mixing (Fig. 6b) are further reconciled with the data of Lewis et al. (1984b) on differences in $P_{\text {max }}^{*}$. Secondly, the relationship allows the pragmatic construction of a model for investigating possible changes in productivity at high resolution across the frontal region (Figs. 8 \& 9).

\section{Controls on frontal productivity}

Productivity is governed by the available irradiance, the distribution of biomass and the physiological state of the phytoplankton community. In highly dynamic systems such as tidal mixing fronts, all these factors respond to changes in the physical environment over a range of time scales. In particular, turbulent dissipation and hence mixing rates vary both spatially and temporally (Fig. 3).

A key time-scale of forcing for the frontal system is the spring-neap cycle of tidal dissipation (e.g. Fig. 3d,f). The cross-frontal transects with SeaSoar thus represent 2 snapshots of a process which was evolving over a 14 d period (Fig. 9). The patterns of biomass and production are likely to be uncoupled and to vary both spatially and temporally throughout the spring-neap cycle. For example, the accumulation of biomass is likely to lag behind the physiological response, and physical accumulation or removal and other factors such as grazing may also be important (LeFevre 1986, Franks 1992a,b, Sharples et al. 2001).

The temperature difference from 5 to $35 \mathrm{~m}\left(\Delta T_{5 \mathrm{~m}-35 \mathrm{~m}}\right)$ was calculated as a crude index of stratification and mixing during the SeaSoar runs (Fig. 9a). Changes in $\Delta T_{5 \mathrm{~m}-35 \mathrm{~m}}$ across the frontal region and for both runs 
accounted for $50 \%$ ( $\mathrm{n}=92)$ of the modelled variability in the depth-integrated production. Changes in the degree of stratification within the frontal region and the response of the phytoplankton physiological state and production at this scale thus appear to be important in governing the productivity of such systems (Pingree et al. 1975).

Overall, the importance of the physiological variability and biomass (at least in the context of the present model applied to SeaSoar data) in driving the patterns of productivity was investigated by regression of the integrated daily rate against various parameters. Combining data from both the frontal SeaSoar transects, the sea-surface chlorophyll concentration accounted for $36 \%$ of the variance in productivity, whereas the near-surface value of $P^{*}{ }_{\text {max }}$ (or equivalently $\sigma_{\mathrm{PSII}}$ for this model), accounted for $55 \%(\mathrm{n}=92)$. When the individual transects were considered, sea-surface chlorophyll and $P^{*}{ }_{\text {max }}$ accounted for 30 and $80 \%$ of the variance in integrated production respectively following spring tides $(\mathrm{n}=55)$. Conversely sea-surface chlorophyll accounted for $64 \%$ of the variance in production following neap tides, while $P^{*}{ }_{\text {max }}$ accounted for only $40 \%(\mathrm{n}=37)$. The importance of variability in the maximum photosynthetic rate for governing changes in production is recognised (Behrenfeld \& Falkowski 1997, Sakshaug et al. 1997). The current study suggests that variability in production around shelf seafronts due to the spring-neap tidal cycle are principally driven by changes in $P^{*}{ }_{\text {max }}$ and are moderated by the accumulation of biomass. The changes in $P^{*}$ max result from variability in nutrient supply and light as a result of the cross-frontal gradient and spring-neap modulation of mixing.

The high-resolution FRRF data utilised in an empirical model calibrated against ${ }^{14} \mathrm{C}$ productivity estimates, therefore allowed investigation of the possible dynamics of phytoplankton growth within the study region (Fig. 9). However, more work is necessary in order to confirm the current observations, particularly with regard to the caveats of the extrapolation exercise, which was based on the observed relationship between $P^{*}{ }_{\text {max }}$ and $\sigma_{\text {PSII }}$, rather than a physiological model. Further studies using more mechanistic approaches are thus clearly desirable. The spring-neap cycle of phytoplankton photosynthesis and growth within these systems also remains to be fully elucidated.

\section{Summary and conclusions}

The ability to observe changes in phytoplankton production at the scales relevant to physical forcing is crucial to furthering our understanding of the dynamics of aquatic ecosystems. The current study highlights the utility of high-resolution fluorescencebased physiological measurements as a means of achieving this goal.

The FRRF technique allowed detailed observations of phytoplankton physiology within a highly dynamic frontal system. It has been shown that a lack of inorganic nutrients limits the photosynthetic efficiency of phytoplankton populations, and hence carbon fixation, on the stratified side of the front. Towards the mixed side of the front, deep vertical mixing may limit production. Physical forcing at a number of scales was shown to result in changes to the physiological state of the phytoplankton populations around the front. The productivity of these frontal systems is therefore strongly affected by tidal processes via changes in physiology. Understanding the net effect of such dynamic variability remains a challenge, as the complete cycle of production, growth and biomass accumulation over spring-neap periods must be considered. However the suggestion that the high levels of chlorophyll in the vicinity of shelf sea fronts are caused by active growth rather than passive accumulation or relaxation from grazing pressure, gains support from this study.

Acknowledgements. The authors wish to thank J. Aiken, P. Boyd and R. Geider for the loan of instruments used in this study and R. Wilton for technical support with FLY. S. Laney kindly made the analysis software (V4) available and provided many helpful discussions on its use. Our thanks to the officers, crew and RVS support staff onboard RRS 'Challenger' for their assistance during Cruise CH145. Comments from an anonymous reviewer considerably improved an earlier version of the manuscript. This work was funded by the Natural Environment Research Council, grant number GR3/11829 and by studentship number GT04/98/MS/267 to C.M.M.

\section{LITERATURE CITED}

Babin M, Morel A, Claustre H, Bricaud A, Kolber Z, Falkowski PG (1996) Nitrogen and irrradiance-dependent variations in the maximum quantum yield of carbon fixation in eutrophic, mesotrophic and oligotrophic marine systems. Deep-Sea Res Part I Oceanogr Res Pap 43: $1241-1272$

Barlow RG, Cummings DG, Gibb SW (1997) Improved resolution of mono- and divinyl chlorophylls $a$ and $b$ and zeaxanthin and lutein in phytoplankton extracts using reverse phase C-8 HPLC. Mar Ecol Prog Ser 161:303-307

Behrenfeld MJ, Falkowski PG (1997) Photosynthetic rates derived from satellite-based chlorophyll concentration. Limnol Oceanogr 42:1-20

Behrenfeld MJ, Bale AJ, Kolber ZS, Aiken J, Falkowski PG (1996) Confirmation of iron limitation of phytoplankton photosynthesis in the equatorial Pacific Ocean. Nature 383:508-511

Behrenfeld MJ, Prášil O, Kolber ZS, Babin M, Falkowski PG (1998) Compensatory changes in Photosystem II electron 
turnover rates protect photosynthesis from photoinhibition. Photosynth Res 58:259-268

Berges JA, Charlebois DO, Mauzerall DC, Falkowski PG (1996) Differential effects of nitrogen limitation on photosynthetic efficiency in photosystems I and II in microalgae. Plant Physiol (Rockv) 110:689-696

Boyd PW, Aiken J, Kolber Z (1997) Comparison of radiocarbon and fluorescence based (pump and probe) measurements of phytoplankton photosynthetic characteristics in the Northeast Atlantic Ocean. Mar Ecol Prog Ser 149: $215-226$

Cleveland JS, Bidigare R, Perry MJ (1989) Maximum quantum yield of photosynthesis in the northwestern Sargasso Sea. J Mar Res 47:869-886

Crofts AR, Baroli I, Kramer D, Taoka S (1993) Kinetics of electron-transfer between $\mathrm{Q}(\mathrm{A})$ and $\mathrm{Q}(\mathrm{B})$ in wild-type and herbicide-resistant mutants of Chlamydomonas reinhardtii. Z Naturforsch Sect C J Biosci 48:259-266

Daneri G, Iriarte A, Garcia VM, Purdie DA, Crawford DW (1992) Growth irradiance as a factor controlling the dark respiration rates of marine phytoplankton. J Mar Biol Assoc UK 72:723-726

Denman KL, Gargett AE (1983) Time and space scales of vertical mixing and advection of phytoplankton in the upper ocean. Limnol Oceanogr 28:801-815

Dewey RK, Crawford WR, Gargett AE, Oakey NS (1987) A microstructure instrument for profiling oceanic turbulence in coastal bottom boundary layers. J Atmos Oceanic Technol 4:288-297

Dubinsky Z, Falkowski PG, Wyman K (1986) Light harvesting and utilisation by phytoplankton. Plant Cell Physiol 27: 1335-1349

Effron B, Gong G (1983) A leisurely look at the bootstrap, the jack-knife and cross-validation. Am Statistn 37:36-46

Falkowski PG (1983) Light-shade adaptation and vertical mixing of marine phytoplankton: a comparative field study. J Mar Res 41:215-237

Falkowski PG (1992) Molecular ecology of phytoplankton photosynthesis. In: Falkowski PG, Woodhead A (eds) Primary productivity and biogeochemical cycles in the Sea. Plenum Press, New York, p 47-67

Falkowski PG, Raven JA (1997) Aquatic photosynthesis. Blackwell Science, Oxford

Falkowski PG, Wyman K, Ley AC, Mauzerall DC (1986) Relationship of steady-state photosynthesis to fluorescence in eukaryotic algae. Biochim Biophys Acta 849:183-192

Falkowski PG, Ziemann D, Kolber Z, Biefang PK (1991) Nutrient pumping and phytoplankton response in a subtropical mesoscale eddy. Nature 352:544-551

Falkowski PG, Greene R, Kolber Z (1994) Light utilization and photoinhibition of photosynthesis in marine phytoplankton. In: Baker NR, Bowyer JR (eds) Photoinhibition of photosynthesis: from molecular mechanisms to the field. Bios Scientific Publishers, Oxford, p 407-432

Fileman ES, Cummings DG, Llewellyn CA (2002) Microplankton community structure and the impact of microzooplankton grazing during an Emiliania huxleyi bloom off the Devon coast. J Mar Biol Assoc UK 82:359-368

Flameling IA, Kromkamp J (1998) Light dependence of quantum yields for PSII charge separation and oxygen evolution in eucaryotic algae. Limnol Oceanogr 43:284-297

Franks PJS (1992a) Phytoplankton blooms at fronts-patterns, scales, and physical forcing mechanisms. Rev Aquat Sci 6:121-137

Franks PJS (1992b) Sink or swim: accumulation of biomass at fronts. Mar Ecol Prog Ser 82:1-12

Geider RJ, Greene RM, Kolber Z, Macintyre HL, Falkowski
PG (1993) Fluorescence assessment of the maximum quantum efficiency of photosynthesis in the Western NorthAtlantic. Deep-Sea Res 40:1205-1224

Geider RJ, MacIntyre HL, Kana TM (1998) A dynamic regulatory model of phytoplanktonic acclimation to light, nutrients, and temperature. Limnol Oceanogr 43:679-694

Genty B, Briantais JM, Baker NR (1989) The relationship between the quantum yield of photosynthetic electron transport and quenching of chlorophyll fluorescence. Biochim Biophys Acta 990:87-92

Grande K, Marra DJ, Langdon C, Heinemann K, Bender ML (1989) Rates of respiration in the light measured using an ${ }^{18} \mathrm{O}$ isotope labelling technique. J Exp Mar Biol Ecol 129: 95-120

Herzig R, Falkowski PG (1989) Nitrogen limitation in Isochrysis galbana. 1. Photosynthetic energy conversion and growth efficiencies. J Phycol 25:462-471

Holligan PM (1981) Biological implications of fronts on the northwest European continental shelf. Philos Trans R Soc Lond A Math Phys Sci 302:547-562

Holligan PM, Williams PJ LeB, Purdie D, Harris RP (1984) Photosynthesis, respiration and nitrogen supply of plankton populations in stratified, frontal and tidally mixed shelf waters. Mar Ecol Prog Ser 17:201-213

Jeffrey SW (1997) Application of pigment methods to oceanography. In: Jeffrey SW, Mantoura RFC, Wright SW (eds) Phytoplankton pigments in oceanography. UNESCO, Paris

Kana TM (1992) Relationship between photosynthetic oxygen cycling and carbon assimilation in Synechococcus WH7803 (Cyanophyta). J Phycol 28:304-308

Kolber Z, Falkowski PG (1993) Use of active fluorescence to estimate phytoplankton photosynthesis in situ. Limnol Oceanogr 38:1646-1665

Kolber Z, Zehr J, Falkowski PG (1988) Effects of growth irradiance and nitrogen limitation on photosynthetic energy conversion in photosystem II. Plant Physiol (Rockv) 88: 923-929

Kolber Z, Wyman KD, Falkowski PG (1990) Natural variability in photosynthetic energy conversion efficiency; a field study in the Gulf of Maine. Limnol Oceanogr 35:72-79

Kolber ZS, Prášil O, Falkowski PG (1998) Measurements of variable chlorophyll fluorescence using fast repetition rate techniques: defining methodology and experimental protocols. Biochim Biophys Acta 1367:88-106

Laws EA (1991) Photosynthetic quotients, new production and net community production in the open ocean. DeepSea Res 38:143-167

Le Fèvre J (1986) Aspects of the biology of frontal systems. Adv Mar Biol 23:163-299

Lewis MR, Cullen JJ, Platt T (1984a) Relationship between vertical mixing and photoadaptation of phytoplankton: similarity criteria. Mar Ecol Prog Ser 15:141-149

Lewis MR, Horne EPW, Cullen JJ, Oakey NS, Platt T (1984b) Turbulent motions may control phytoplankton photosynthesis in the upper ocean. Nature 311:49-50

Ley AC, Mauzerall D (1982) Absolute absorption cross sections for photosystem II and the minimum quantum requirement for photosynthesis in Chlorella vulgaris. Biochim Biophys Acta 680:95-106

Marra J (2002) Approaches to the measurement of plankton production. In: Williams PJ LeB, Thomas DN, Reynolds CS (eds) Phytoplankton productivity. Blackwell Science, Oxford, p 78-108

Moore CM (2002) Small scale physical processes and phytoplankton growth in shelf seas. PhD thesis, University of Southampton

Myers JE (1980) On the algae: thoughts about physiology and 
measurements of efficiency. In: Falkowski PG (ed) Primary productivity in the sea. Plenum Press, New York Olaizola M, LaRoche J, Kolber Z, Falkowski PG (1994) Nonphotochemical quenching and the diadinoxanthin cycle in a marine diatom. Photosynth Res 41:357-370

Olson RJ, Chekalyuk AM, Sosik HM (1996) Phytoplankton photosynthetic characteristics from fluorescence induction assays of individual cells. Limnol Oceanogr 41:1253-1263

Oxborough K, Baker NR (1997) Resolving chlorophyll a fluorescence images of photosynthetic efficiency into photochemical and non-photochemical components - calculation of $\mathrm{qP}$ and $F_{\mathrm{v}}{ }^{\prime} / F_{\mathrm{m}}{ }^{\prime}$ without measuring $F_{0}{ }^{\prime}$. Photosynth Res 54:135-142

Parkhill JP, Maillet G, Cullen JJ (2001) Fluorescence-based maximal quantum yield for PSII as a diagnostic of nutrient stress. J Phycol 37:517-529

Pingree RD (1979) Baroclinic eddies bordering the Celtic Sea in late summer. J Mar Biol Assoc UK 59:689-698

Pingree RD, Pugh PR, Holligan PM, Forster GR (1975) Summer phytoplankton blooms and red tides along tidal fronts in the approaches to the English Channel. Nature 258: 672-677

Prášil O, Kolber ZS, Berry JA, Falkowski PG (1996) Cyclic electron flow around photosystem II in vivo. Photosynth Res 48:395-410

Raven JA, Johnston AM (1991) Mechanisms of inorganiccarbon acquisition in marine phytoplankton and their implications for the use of other resources. Limnol Oceanogr 36:1701-1714

Sakshaug E, Bricaud A, Dandonneau Y, Falkowski PG and 5 others (1997) Parameters of photosynthesis: definitions, theory and interpretation of results. J Plankton Res 19: $1637-1670$

Sharples J, Simpson JH (1996) The influence of the springsneaps cycle on the position of shelf sea fronts. Coast Estuar Stud 53:71-82

Editorial responsibility: Otto Kinne (Editor),

Oldendorf/Luhe, Germany
Sharples J, Moore CM, Rippeth TP, Holligan PM, Hydes DJ, Fisher NR, Simpson JH (2001) Phytoplankton distribution and survival in the thermocline. Limnol Oceanogr 46: 486-496

Simpson JH, Bowers DG (1981) Models of stratification and frontal movement in shelf seas. Deep-Sea Res Part A Oceanogr Res Pap 28:727-738

Sournia A, Belin C, Billard C, Martial C and 5 others (1992) The repetitive and expanding occurrence of a green bloom-forming dinoflagellate (Dinophyceae) on the coasts of France. Crypotogam Algol 13:1-13

Suggett D, Kraay G, Holligan P, Davey M, Aiken J, Geider R (2001) Assessment of photosynthesis in a spring cyanobacterial bloom by use of a fast repetition rate fluorometer. Limnol Oceanogr 46:802-810

Sukenik A, Bennett J, Falkowski PG (1987) Light-saturated photosynthesis-limitation by electron transport or carbon fixation? Biochim Biophys Acta 891:205-215

Tassan S, Ferrari GM (1995) An alternative approach to absorption measurements of aquatic particles retained on filters. Limnol Oceanogr 40:1358-1368

Vassiliev IR, Prášil O, Wyman K, Kolber Z, Hanson AK, Prentice J, Falkowski PG (1994) Inhibition of PSII photochemistry by PAR and UV radiation in natural phytoplankton communities. Photosynth Res 42:51-64

Videau C (1987) Primary production and physiological state of phytoplankton at the Ushant tidal front (west coast of Brittany, France). Mar Ecol Prog Ser 35:141-151

Welschmeyer NA (1994) Fluorometric analysis of chlorophyll $a$ in the presence of chlorophyll $b$ and phaeopigments. Limnol Oceanogr 39:1985-1992

Williams PJ LeB, Robinson C, Sondergaard M, Jespersen AM, Bentley TL, Lefevre D, Richardson K, Riemann B (1996) Algal C-14 and total carbon metabolism, 2. Experimental observations with the diatom Skeletonema costatum. J Plankton Res 18:1961-1974

Submitted: September 27, 2002; Accepted: April 16, 2003 Proofs received from author(s): August 25, 2003 